\title{
The wear mechanisms occurring in a labyrinth seal/abradable contact depending on the incursion depth parameter
}

\author{
C. Delebarre ${ }^{1,2, a}$, V. Wagner ${ }^{2}$, J.Y. Paris ${ }^{2}$, G. Dessein ${ }^{2}$, J. Denape ${ }^{2}$ \\ AND J. GURT-SANTANACH ${ }^{1}$ \\ 1 TURBOMECA, Avenue Joseph Szydlowski, 64510 Bordes, France \\ 2 Université de Toulouse, Laboratoire Génie de Production, École Nationale d'Ingénieurs de Tarbes, 47 Avenue d'Azereix, \\ BP 1629, 65016 Tarbes Cedex, France
}

Received 31 October 2014, Accepted 2 December 2015

\begin{abstract}
The contact behavior of an abradable coating (Al-Si 6\%) and a labyrinth seal tooth (stainless steel) in a turbo-engine application was studied as a function of the incursion depth parameter, during labyrinth seal/abradable interaction. A controlled and a gradual increase of the labyrinth seal incursion (by step of $50 \mu \mathrm{m}$ ) is performed to obtain the chronological contact evolution under severe operating tribological conditions. The labyrinth seal/abradable contact experiments were conducted on a dedicated test rig able to reach high contact speeds from 0 to $130 \mathrm{~m} . \mathrm{s}^{-1}$. To complete contact forces measurement during tests, a suitable instrumentation (acoustic emission sensor, accelerometer, thermocouples, etc.) is developed and coupled as close as possible of the interaction area. The experimental results from the both severe tribological conditions are presented by an analysis of signals recorded during contact tests. Macrographic and micrographic rub-groove observations of post tests samples, coupled with recorded signals from the contact complete the Al-Si $6 \%$ behavior study. A wear process description using the third body approach has been proposed to sum up the whole tribological results. Two different varieties of particles production have been identified; a ductile and an adhering layer on the rub-groove bottom and pulverulent fine powder particles, thus providing two different kind of third body and two different material flows.
\end{abstract}

Key words: Labyrinth seal / abradable coating / wear mechanisms / third body / experimental study

\section{Introduction}

The clearance minimization between rotary parts and stationary parts in turbo-engine air systems is a method, developed by the turbo machinery manufacturers, to improve the turbo-engine efficiency by a precise control of the airflow direction $[1,2]$. In the secondary air and sealing systems, the control of pressure differences and the levels of cooling between the engine modules are crucial to the turbo-engine operation. During operation, a turboengine is subjected to successive start and stop cycles, thermal expansion, vibration, mechanical loading, which might create rotor-stator displacements and producing undesirable interactions $[3,4]$. The clearances between dynamic sealing systems of rotating and stationary components have always been important in controlling leakage, and if the clearance is too small, a rub may occur which may damage one or both members. These dynamic sealing

\footnotetext{
${ }^{a}$ Corresponding author:

corentin.delebarre@enit.fr
}

systems are composed of a particular type of rotary seal, called the labyrinth seal. This rotary seal controls the cooling airflow through the heated section of the engine. The labyrinth seal is a non contacting circumferential seal located primarily on the rotating shafts between the compression stages and are composed of several annular teeth. They are integral parts of the motor shaft [5], in which a tortuous flow path between the stationary and rotating parts creates a series of pressure drops to reduce the leakage and maintains the pressure balance on the rotor shaft system. Minimal seal clearance is necessary to achieve a labyrinth seal effectiveness and is controlled by the use of an abradable material (rub tolerant material) coated on the housing support. To protect the rotating/stationary parts during undesirable interactions and precisely of incursions of the labyrinth teeth onto bare metal, the insertion of an abradable material layer a few millimeters thick on the housing support has been widely recognized as a robust solution. The turbo-engine housing is coated with a sacrificial abradable material that is thermally sprayed and is composed of a metal phase and a self-lubricating 


\section{Nomenclature}

\begin{tabular}{|ll|}
\hline$A E$ & Acoustic Emission \\
$D$ & Abradable flow, $\mathrm{mm}^{3} \cdot \mathrm{s}^{-1}$ \\
$D_{p}$ & Incursion depth, $\mu \mathrm{m}$ \\
$F$ & Feed-rate, mm.rev \\
$F F T$ & Fast Fourier Transform \\
$f_{n}$ & Normal force component, $\mathrm{N}$ \\
$f_{t}$ & Tangential force component, $\mathrm{N}$ \\
$f_{r 1}$ & Test series No. 1 rotational frequency, $\mathrm{Hz}$ \\
$f_{r 2}$ & Test series No. 2 rotational frequency, $\mathrm{Hz}$ \\
$L$ & Rubbed length, mm \\
$N_{b}$ & Number of labyrinth seal rotation, rev \\
$R_{1}$ & Internal radius of the tube coated with \\
& abradable, mm \\
$R_{2}$ & Radius of the labyrinth seal tooth, mm \\
$S T F T$ & Short-Time Fourier Transform \\
$t$ & Interaction time, $\mathrm{s}$ \\
$V_{i n c}$ & Labyrinth seal incursion speed, mm.s ${ }^{-1}$ \\
$V_{r}$ & Labyrinth seal rotational speed, rpm \\
$V_{t}$ & Labyrinth tip speed, m.s ${ }^{-1}$ \\
$\alpha$ & Contact angular length, rad \\
$\mu$ & Friction coefficient \\
$\xi$ & Mechanical clearance, $\mu \mathrm{m}$ \\
$\Omega$ & Labyrinth seal angular velocity, rad.s \\
\hline
\end{tabular}

non-metal phase that provide a high porosity rate and offer a good balance between the abradability and erosion resistance [6]. The use of this type of abradable coating is widespread in other extensively researched turbo-engine applications such as use in blade tips and compressor housing $[7,8]$ and has encouraged turbo-engine manufacturers to characterize the abradable behavior subjected to rotor-stator interactions.

Today, the research activities are mainly focused on experimental and numerical studies helping to characterize the aerodynamics seal performance and leakage level generated by rub-grooves left by the labyrinth seal teeth [9-11]. The effect of the clearance on leakage, the effect of tooth profiles, of tooth thickness, of the geometry of the labyrinth seal design and on the rub-groove, on labyrinth seal performance have been quantify [12-15]. Concerning the abradable coating behavior during the labyrinth seal interaction, and specially focus on the contact understanding, different kinds of test rigs have been developed. A full-scale facility based on a grinding machine has been developed to study the behavior of abradable materials (mica filled tetrafluoroethylene (TFE), silicone rubber, aluminium polyester and nickel graphite) in contact with a labyrinth seal at relative speeds up to $25 \mathrm{~m} . \mathrm{s}^{-1}$ and $130 \mathrm{~m} . \mathrm{s}^{-1}$ respectively $[16,17]$. The authors established a "good abradability" condition for the tested materials by defining a ratio corresponding to the depth of the groove divided by the material loss of the labyrinth. An additional condition describing abradability was defined by Mutazim et al. [18] by characterizing the rub-groove geometry of seven abradable materials (aluminium, Al-bronze, Al-Si-polyester, Al-bronze-polyester,
Al-Si-polyimide, Cu-Sn-Bi, Cu-Sn-Pb) subjected to an unlubricated contact with a four teeth labyrinth seal and using a specific full-scale test rig. Additional experiments developed by Sulzer Innotec and Sulzer Metco [19] use a specific test rig adapted to the application of labyrinth/abradable interactions which consists of an alloy disc that accommodates four continuous seal trips on the outer circumference, a movable specimen coated with an abradable material and a heating device.

The present study is based on a first assessment of high-speed mechanical interactions between an Alloy 718 labyrinth seal and an abradable Al-Si $6 \%$ coating initiated by Delebarre et al. [20], in which an original test rig was specifically designed to simulate these interactions in realistic operating conditions. The test rig has been specially instrumented to allow contact forces, temperature, acceleration and acoustic emission measurements for a high frequency analysis of the Al-Si $6 \%$ wear mechanism subjected to labyrinth seal tooth interactions. Physicochemical, mechanical properties and experimental interaction data were considered to establish relationships between the Al-Si $6 \%$ wear behavior and microstructural characteristics. According to study conducted by Hase et al. [21], an interpretation of the acoustic emission data have been performed using a time-frequency analysis of the interaction to identify the specific frequency signatures associated to the Al-Si $6 \%$ wear mechanisms encountered [21]. The use of a time-frequency representation (the short time Fourier transform) enables the identification of active frequencies during the interaction [22]. A third body approach was considered for a more complete description of the whole wear mechanisms through the concept of tribological circuit.

\section{Contact experiments and materials}

\subsection{Test rig description}

A new high-speed test rig was designed to simulate the interaction between labyrinth seals and abradable coatings in similar turbo-engine operating conditions (Fig. 1a). As this test rig design and its special contact forces instrumentation have been fully detailed in reference [20], this section essentially describes the main features and technical improvements used in the following study. The capabilities of a 5-axis UCP600 VARIO milling machine from Mikron are used to simulate the turbo-engine interactions between the labyrinth seals and abradable coatings in realistic operating conditions. The specificity of the 5-axis milling machine lies in the fact that it is fitted with a unique magnetic bearings spindle which allows a maximum rotation speed of $40000 \mathrm{rpm}$, corresponding to a tangential contact speed ranged from 0 of $130 \mathrm{~m} . \mathrm{s}^{-1}$. The test rig is primarily composed of a labyrinth seal sample representative of an actual motor shaft section part which is shrinking on a HSK-50 tool holder instead of a cutting tool. The labyrinth seal sample contact is performed inside a special tube sample coated in the inner periphery with abradable materials 


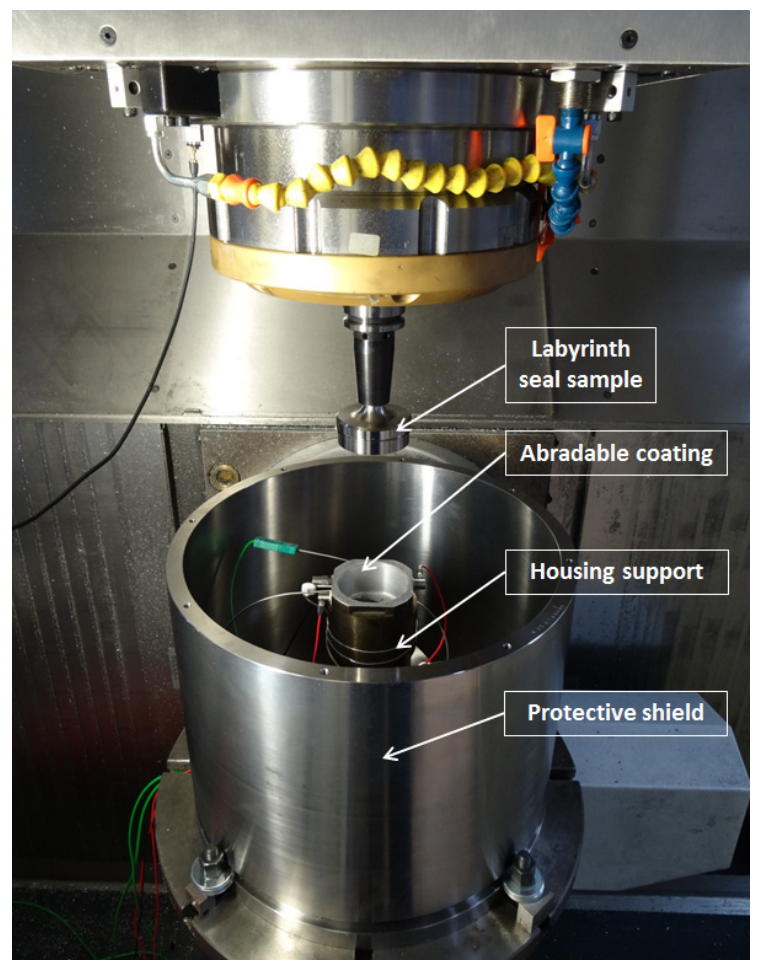

(a)

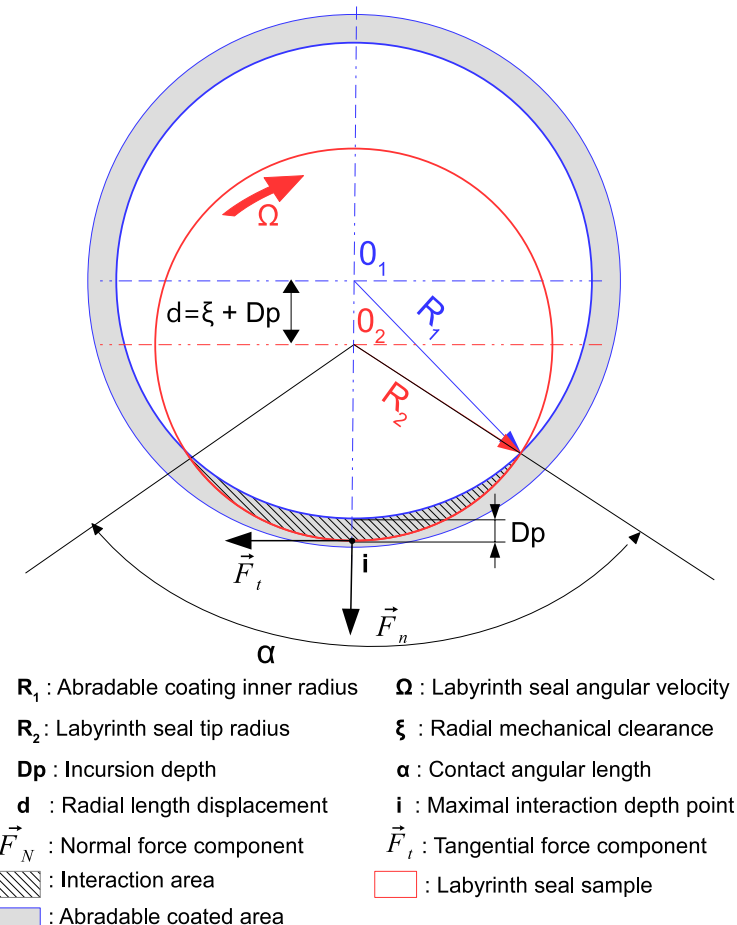

(b)

Fig. 1. (a) Test rig overview without protective shield cover, (b) simplified dynamic model of the interaction.

representative of the turbo-engine housing facing the labyrinth seals in the secondary airflow section of a turboengine. The labyrinth seal sample is precisely positioned inside the tube to minimize the default concentricity during the interactions. The dynamic properties of the machine tool table actuator achieve a radial incursion speed range of $0.001 \mathrm{~mm} . \mathrm{s}^{-1}$ to $25 \mathrm{~mm} . \mathrm{s}^{-1}$ fixed by an incursion depth and mechanical clearance based on the real engine conditions.

The contact between a labyrinth seal and an abradable coating is theoretically characterized by an interaction area induced by the radial incursion of a circular tooth in a tube (Fig. 1b). We consider a simplified dynamic model consisting of a stationary tube coated with an abradable material (housing support + abradable coating) of radius $R_{1}$ and a concentric labyrinth seal sample with a tooth tip of radius $R_{2}$. The mechanical clearance between the labyrinth seal tooth tip and the abradable coating at rest is equal to $\xi=R_{1}-R_{2}$. The contact interaction is produced by a sudden radial displacement of the abradable sample center $\left(O_{1}\right)$ relative to the rotor center $\left(O_{2}\right)$. This radial displacement is defined by a target length $d$ and an incursion speed $V_{\text {inc }}$. The interaction area is then characterized by an incursion depth $D_{p}$ and a contact angular length $\alpha$. The contact angular length is easily obtained from Figure 1b as:

$\alpha=2 \times\left(\Pi-\operatorname{arcos}\left(\frac{\left(\left(\left(R_{2}-R_{1}\right)+D p\right)^{2}+R_{1}^{2}-R_{2}^{2}\right)}{\left.2 \times R_{1} \times\left(\left(R_{2}-R_{1}\right)+D_{p}\right)\right)}\right)\right)$
In order to precisely investigate the abradable coating behavior in contact with the labyrinth teeth tip, the test rig configuration was modified with respect to the fullscale configuration. This modification mainly concerned the labyrinth seal specimen design. The labyrinth seal sample geometry has been simplified and is composed of a single circular tooth that is $65.8 \mathrm{~mm}$ in external diameter (Fig. 2a). This labyrinth seal sample configuration simplifies the interaction area and eliminates the juxtapose teeth interaction effects on a single labyrinth seal, such as thermal confinement or different contact behaviors induced by a rotor unbalance. The labyrinth seal tooth of trapezoidal section remains unchanged (Fig. 2b). The trapezoidal section of the labyrinth seal tooth induces a complex contact geometry which evolves according to the incursion depth. The machining precision of the labyrinth seal teeth (the geometric tolerances and unbalance), the positioning precision of the test pieces and the spindle stiffness (hypothesized to be infinite during contact), have an important effect on the mechanical clearance when the rotor is spun up at a rotational speed $\Omega$.

A special instrumentation has been developed on the test rig to provide additional macroscopic and microscopic data focused on the abradable behavior during the interactions. First, a simple voltage circuit has been set up to identify the contact time between the labyrinth seal tooth and the abradable coating to avoid the labyrinth seal incursion depth imprecision during tests (Fig. 3a). Actually, an acquisition device records the voltage variations during the tests induced by the opening and closing of the 


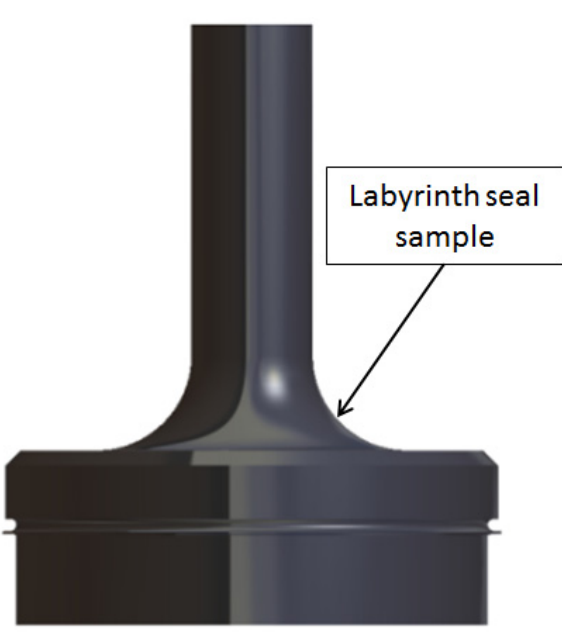

(a)

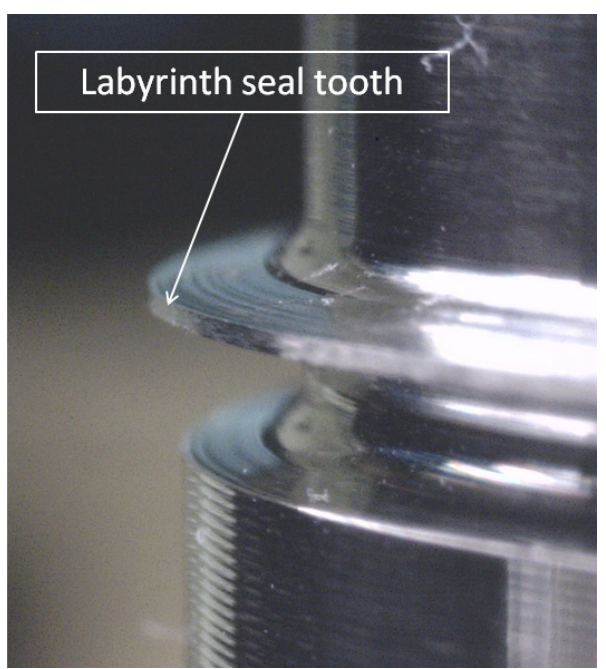

(b)

Fig. 2. (a) Labyrinth seal sample design, (b) labyrinth seal tooth geometry.

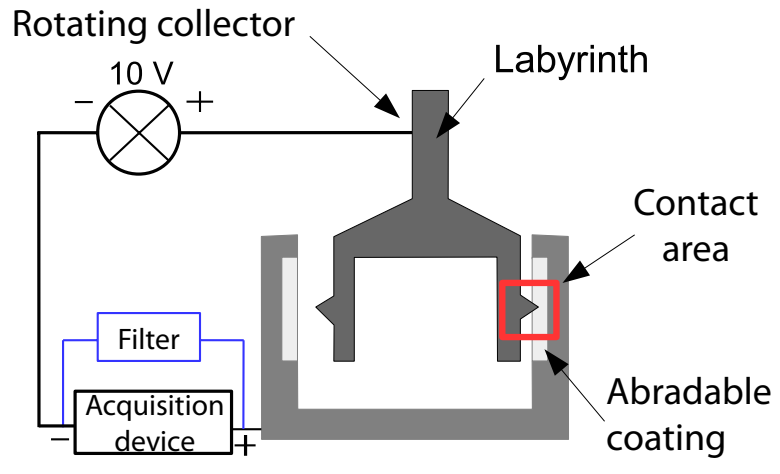

(a)

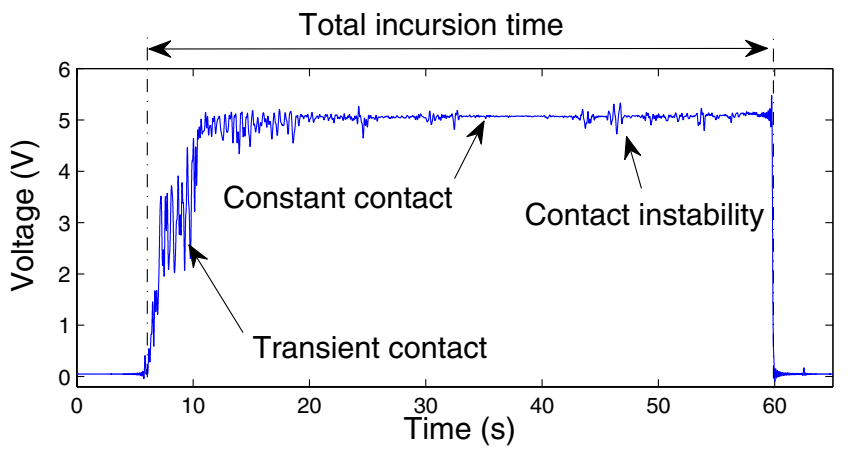

(b)

Fig. 3. (a) Schematic diagram of the voltage circuit, (b) typical interaction voltage signal after dynamic filtering.

circuit according to the labyrinth seal tooth contact and abradable coating. A dynamic filter is developed to reduce the undesirable electromagnetic disruptions caused by the magnetic bearing spindle use (Fig. 3b).

Additional sensors are settled on the abradable test sample as close as possible of the interaction area to complete the study (Fig. 4). A single axis accelerometer ICP 352C03 from PCB Piezotronics is fixed to the abradable sample to record low-frequency vibration phenomena at a sampling frequency of $15 \mathrm{kHz}$.

To complete the vibration study and most significantly to record the transient elastic waves due to local micro-displacements within the abradable material [23], a high-frequency acoustic emission sensor Micro80 from MISTRAS Group records continuously at a sampling frequency of $1 \mathrm{MHz}$. Finally, a thermocouple is located in the abradable sample at the abradable/substrate interface to record the temperature evolution during the experiment. All the sensor records are synchronized simultaneously using an autonomous NI CompactDAQ 9138 fitted with the appropriate acquisition devices. All these sensors add up to the special contact force instrumentation developed to record the interaction forces during the tests.

The control current signals of the magnetic bearings spindle are recorded and processed as values of the contact forces. The processing is the result of a preliminary study designed to calibrate the recorded signals using a Kistler type 9272 dynamometer. The force measurements are based on the calculation of the normal and tangential components of the overall forces applied on the labyrinth seal sample. Details of the special instrumentation were discussed in the previous study and will not be repeated here. Figure 5 presents the superimposition of the typical signals recorded during a low incursion speed interaction.

\subsection{Test materials}

The labyrinth seal sample used for this test campaign is made of a stainless steel $\mathrm{X} 5 \mathrm{CrNiCuNb} 17-04$ and its chemical composition is presented in Table 1.

The Al-Si $6 \%$ abradable coating is thermally sprayed inside the housing support and precisely onto a bond coat 
C. Delebarre et al.: Mechanics \& Industry 17, 601 (2016)

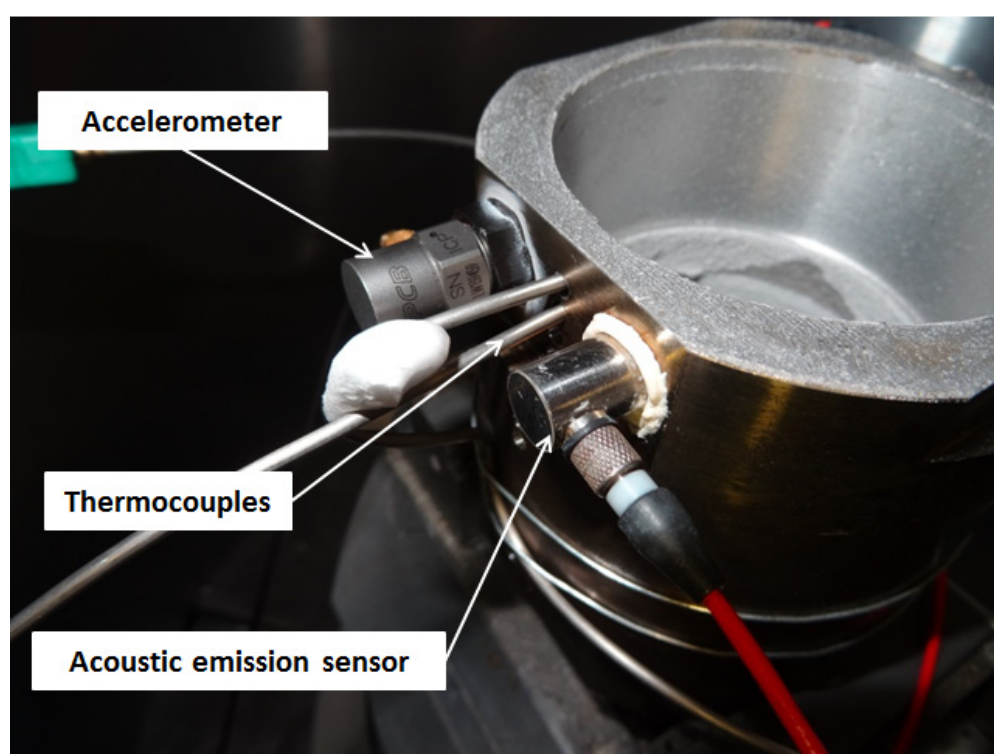

Fig. 4. Side view of the housing support instrumented.
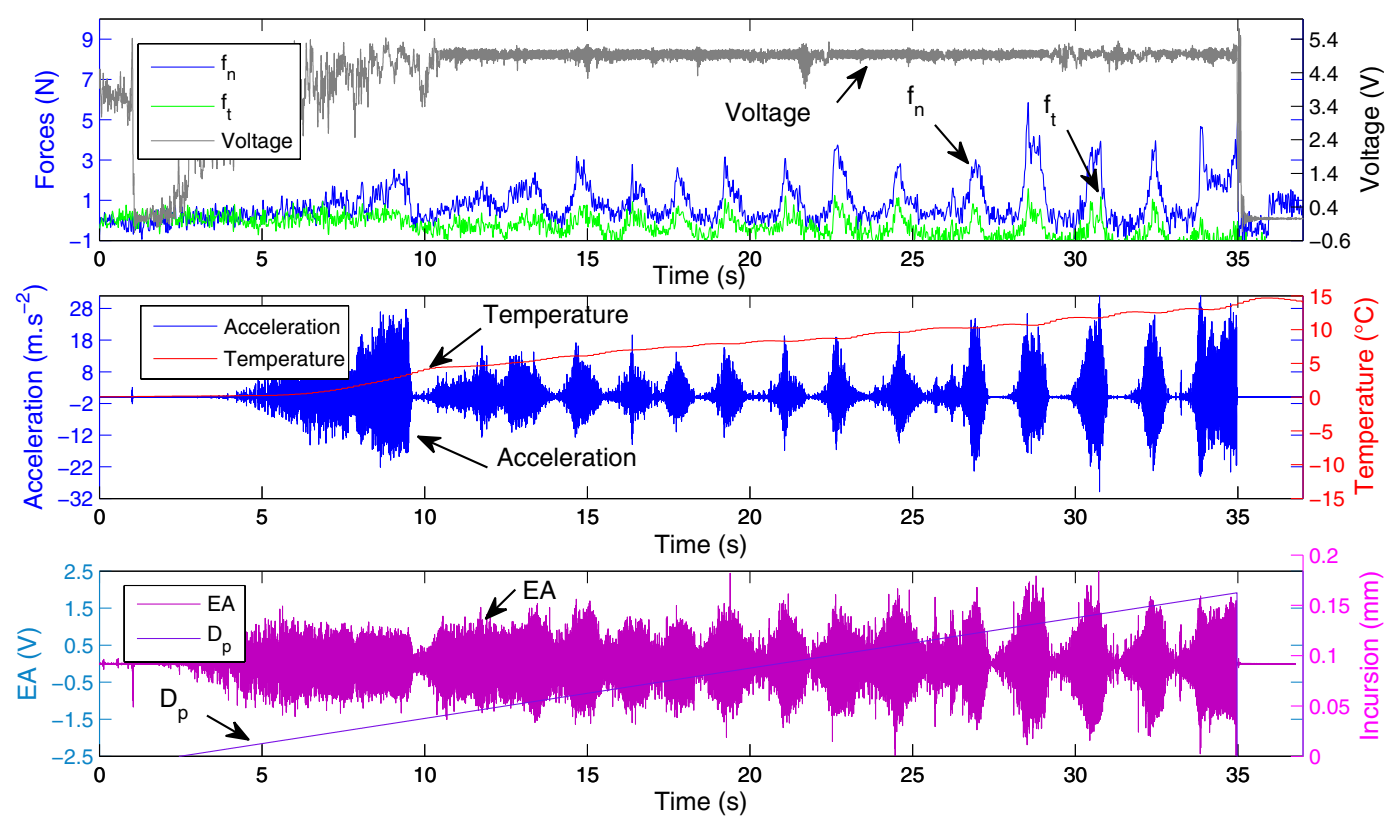

Fig. 5. Typical signals recorded and superimposed for the tests No. $1 \mathrm{~b}\left(V_{p}=37500 \mathrm{rpm}, V_{\text {inc }}=0.005 \mathrm{~mm} . \mathrm{s}^{-1}, D_{p}=165 \mu \mathrm{m}\right)$.

Table 1. Chemical composition and material properties of $\mathrm{X} 5 \mathrm{CrNiCuNb} 17-04$.

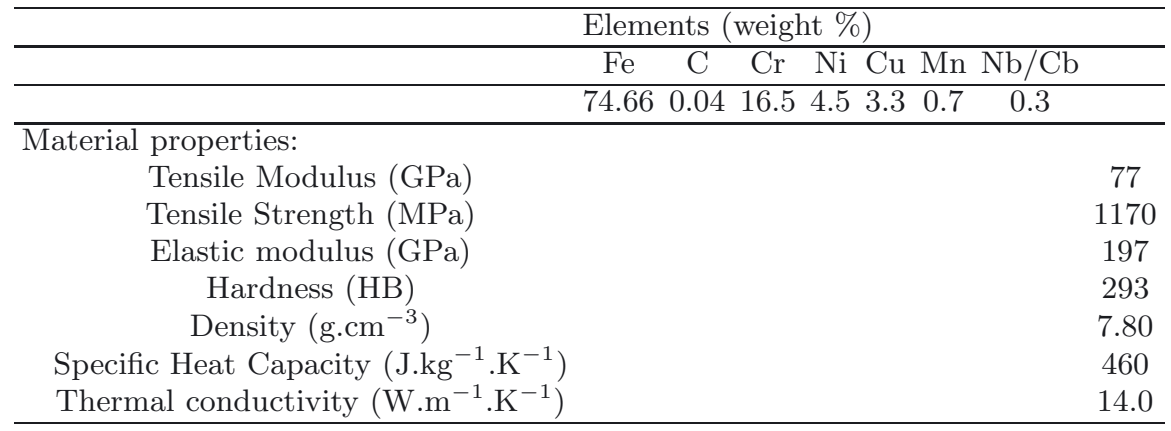




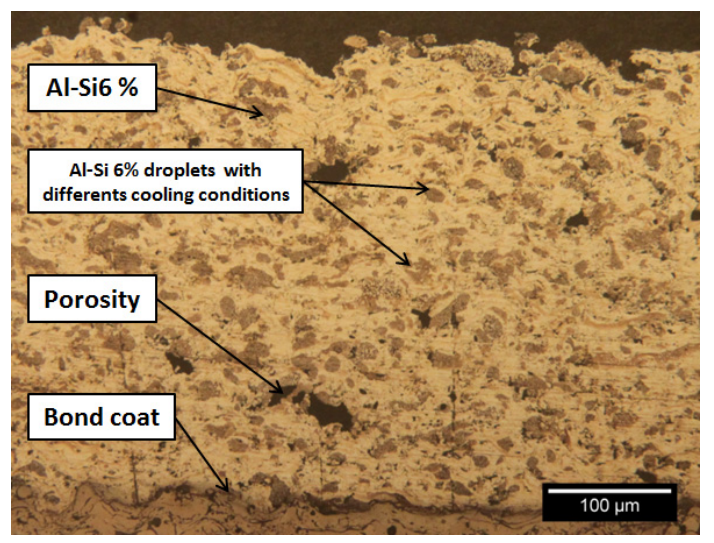

(a)

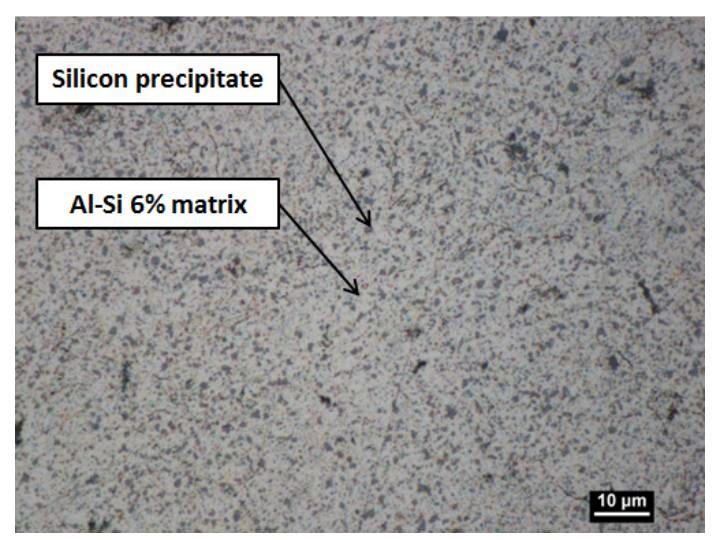

(b)

Fig. 6. Observation of the Al-Si 6\% coating microstructure: (a) after a Keller attack under an optical micrograph [24], (b) after a stress relieving thermal treatment [24].

at approximately 20 to $150 \mu \mathrm{m}$ thick. The Al-Si $6 \%$ coating was particularly heterogeneous and porous because of the abradable composition and spraying method. The raw Al-Si 6\% microstructure (post thermal spraying), consists of a stack of Al-Si $6 \%$ droplets of various morphologies (Fig. 6a). These various droplets morphologies convey different states of the Al-Si $6 \%$ sprayed upon the impact on the substrate (liquid, unmelted, semi-liquid etc) and different cooling conditions. Once coated, a stress relieving thermal treatment is applied on the Al-Si $6 \%$ at $450{ }^{\circ} \mathrm{C}$, holding for one hour, to reduce the residual stresses caused by the coating sudden cooling previously thermally sprayed. After several Al-Si $6 \%$ micrographic and microstructural analysis performed by Prilieux et al. [24], the stress relieving provides a microstructure alteration of the coating. Indeed, a microstructure homogenization is observed and characterized by silicon precipitates in the resulting Al-Si 6\% matrix (Fig. 6b).

In that case, the stress relieving thermal treatment applied on the Al-Si 6\% coating is described as a fullyfledged heat treatment. To control the abradable thickness (approximately $1 \mathrm{~mm}$ ) and the internal diameter, the housing support was machined by turning. This machining process defines the mechanical clearance between the abradable coating and the labyrinth seal teeth.

\subsection{Test parameters}

The control test parameters used to simulate on the test rig the labyrinth seal and abradable coating interactions are the rotational speed $V_{r}$, the incursion speed $V_{i n c}$ and the incursion depth $D_{p}$. A test matrix was selected in the previous preliminary study to cover various conditions encountered in a turbo-engines such as engine vibrations, excessive mechanical loading or thermal expansion. The labyrinth seal rotation speeds were selected and defined as representative contact velocities during a turbo-engine operation $\left(V_{r}=37500,12500\right.$, and $\left.5000 \mathrm{rpm}\right)$. The radial incursion speeds were fixed, thus defining two types of contact: a high incursion speed $V_{\text {inc }}=9.41 \mathrm{~mm} . \mathrm{s}^{-1}$ and a low incursion speed $V_{i n c}=0.005 \mathrm{~mm} . \mathrm{s}^{-1}$. In this study, the test matrix is only focused on two conditions, simulated with a pair of test parameters, and are qualified as "severe tribological conditions" for the affected abradable coating. The term "severe" is associated to a significant value of a tribological parameter which could significantly affect the Al-Si $6 \%$ behavior. These two severe tribological conditions have been identified and chosen by expressing new input parameters as a function of the incursion speed $V_{\text {inc }}$ and the rotational speed $V_{r}$. The new inputs parameters are listed in Table 2 and correspond to typical parameters used to characterized a tribological interaction.

Figure 7 presents the 3-D interpolated surfaces corresponding to new input parameters plotted as a function of $V_{i n c}$ and $V_{r}$. A high rubbed length $L$ associated to a high number of labyrinth seal rotations $N_{b}$ describe the first severe rubbing condition (test series No. 1) and are simulated with a high rotational speed $V_{r}=37500 \mathrm{rpm}$ and a low incursion speed $V_{i n c}=0.005 \mathrm{~mm} . \mathrm{s}^{-1}$. A significant feed-rate $F$ leading to a high abradable flow $D$ are obtained with a low rotational speed $V_{r}=5000 \mathrm{rpm}$ and a high incursion speed $V_{i n c}=9.41 \mathrm{~mm} . \mathrm{s}^{-1}$, and constitute a severe wear condition (test series No. 2).

The labyrinth seal tooth dynamics for both incursion speeds test conditions $\left(V_{i n c}=0.005 \mathrm{~mm} \cdot \mathrm{s}^{-1}\right.$ and $V_{i n c}=$ $\left.9.41 \mathrm{~mm} . \mathrm{s}^{-1}\right)$ are plotted in Figure 8.

Contrary to the high incursion speed tests, the labyrinth seal velocity is kept constant during the low incursion speed interaction (Fig. 8a). In fact, the machine tool capabilities cannot provide to keep an identical labyrinth seal velocity with a too low target length $d$. The low dynamic changes may be observed in the incursion depth rise time and on the maximal velocity value.

Nevertheless, the interaction test is carried out with a reduced labyrinth seal incursion speed until the desired incursion depth. Each severe wear condition have been independently simulated using four different incursion depths $D_{p}$, separated from each other a distance of $50 \mu \mathrm{m}$. The general view was to obtain a general overview of the in- 
Table 2. New input parameters description.

\begin{tabular}{ll}
\hline Number of labyrinth seal rotations (rev) & $N_{b}=\left(V_{r} / 60\right) * t$ \\
Feed-rate $\left(\mathrm{mm} \cdot \mathrm{rev}^{-1}\right)$ & $F=V_{i n c} / V_{r}$ \\
Rubbed length $(\mathrm{mm})$ & $L=\sum_{i=0}^{N_{b}} \alpha_{i} R_{1}$ with $\alpha_{i}=$ the contact angular length at the turn $i$ \\
Abradable flow $\left(\mathrm{mm}^{3} \cdot \mathrm{s}^{-1}\right)$ & $D=V_{\text {wear }} / t$ with $V_{\text {wear }}=$ theoretical volume of worn abradable \\
& calculated with CAD model \\
\hline
\end{tabular}

(a) Number of revolution vs $V_{\text {inc }}$ vs $V_{r}$

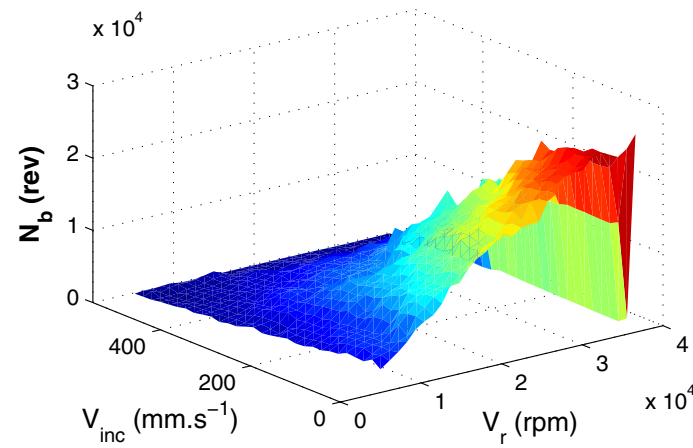

(c) Feed-rate vs $V_{\text {inc }}$ vs $V_{r}$

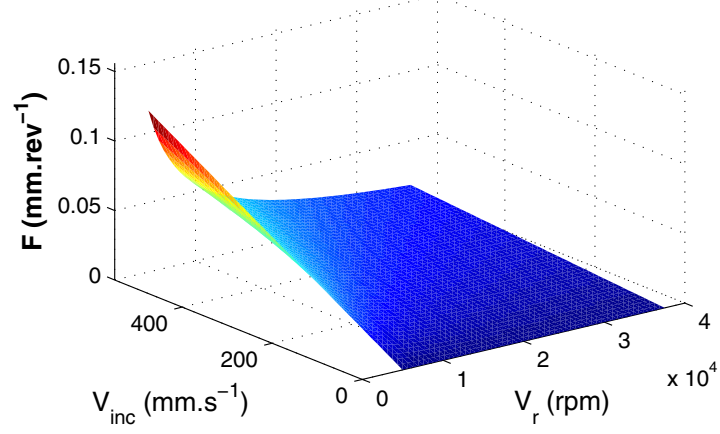

(b) Rubbed length vs $\mathrm{V}_{\text {inc }}$ vs $\mathrm{V}_{\mathrm{r}}$

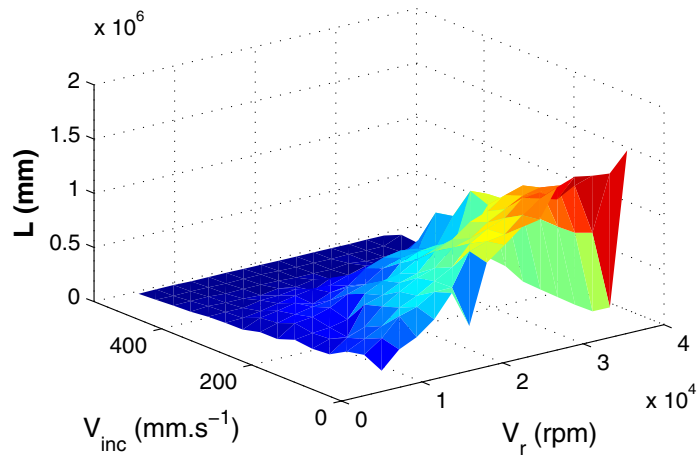

(d) Abradable flow vs $\mathrm{V}_{\text {inc }}$ vs $\mathrm{V}_{\mathrm{r}}$

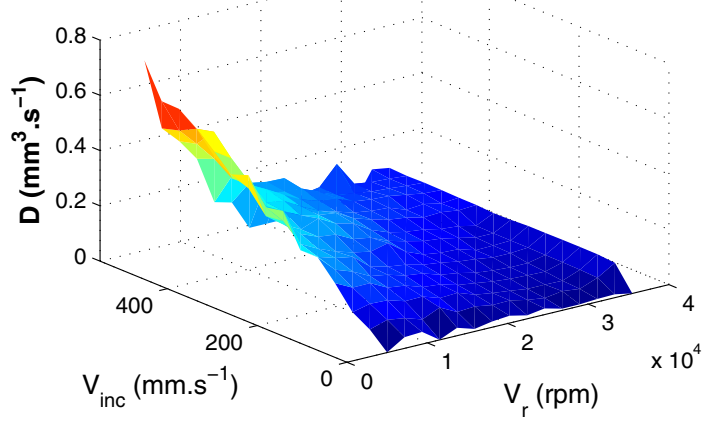

Fig. 7. 3-D interpolated surfaces corresponding to the new input parameters highlighting the severe rubbing condition (a) and (b) and the severe wear condition (c) and (d).

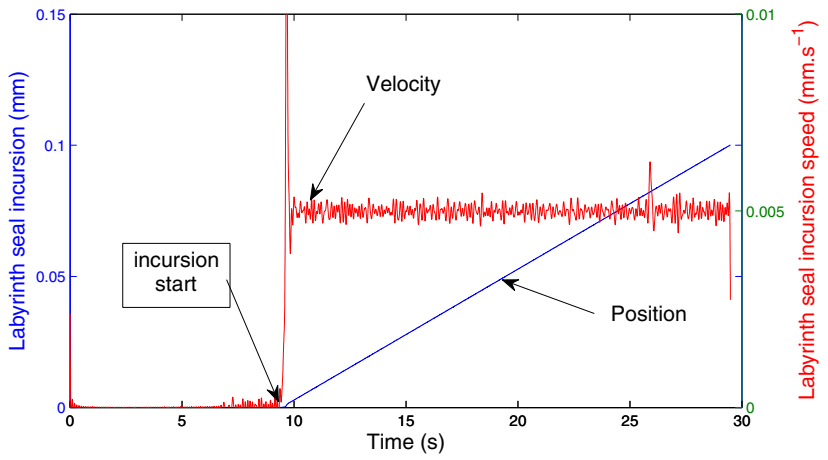

(a)

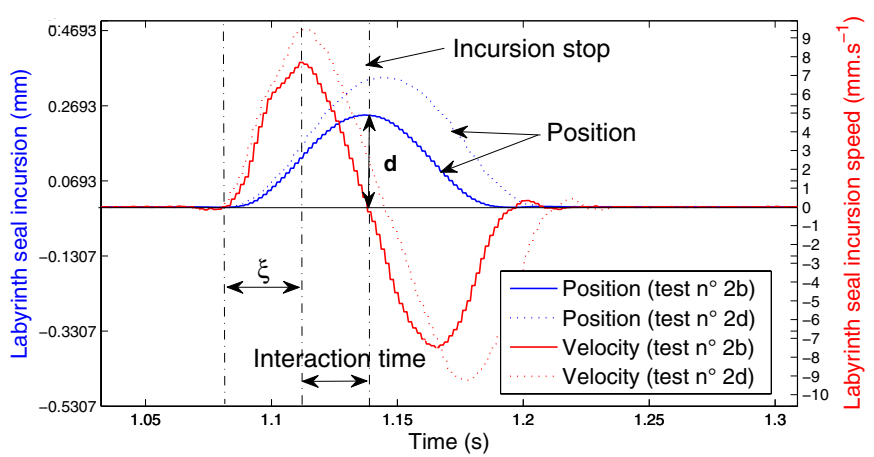

(b)

Fig. 8. Labyrinth seal tooth dynamic: (a) for the low incursion, (b) for the high incursion speed tests. 
Table 3. Test matrix.

\begin{tabular}{cccccc}
\hline $\begin{array}{c}\text { Tests } \\
\text { No. }\end{array}$ & $\begin{array}{c}\text { Rotational speed } \\
V_{r}(\mathrm{rpm})\end{array}$ & $\begin{array}{c}\text { Labyrinth tip speed } \\
V_{t}\left(\mathrm{~m} \cdot \mathrm{s}^{-1}\right)\end{array}$ & $\begin{array}{c}\text { Incursion speed } \\
V_{\text {inc }}\left(\mathrm{mm} \cdot \mathrm{s}^{-1}\right)\end{array}$ & $\begin{array}{c}\text { Incursion depth } \\
D_{p}(\mu \mathrm{m})\end{array}$ & $\begin{array}{c}\text { Interaction time } \\
t(\mathrm{~s})\end{array}$ \\
\hline 1a & 37500 & 130 & 0.005 & 115 & 24 \\
1b & 37500 & 130 & 0.005 & 165 & 34 \\
1c & 37500 & 130 & 0.005 & 215 & 44 \\
1d & 37500 & 130 & 0.005 & 265 & 54 \\
\hline 2a & 5000 & 17 & 9.41 & 62 & 0,031 \\
2b & 5000 & 17 & 9.41 & 113 & 0.044 \\
2c & 5000 & 17 & 9.41 & 165 & 0.051 \\
2d & 5000 & 17 & 9.41 & 229 & 0.057 \\
\hline
\end{tabular}
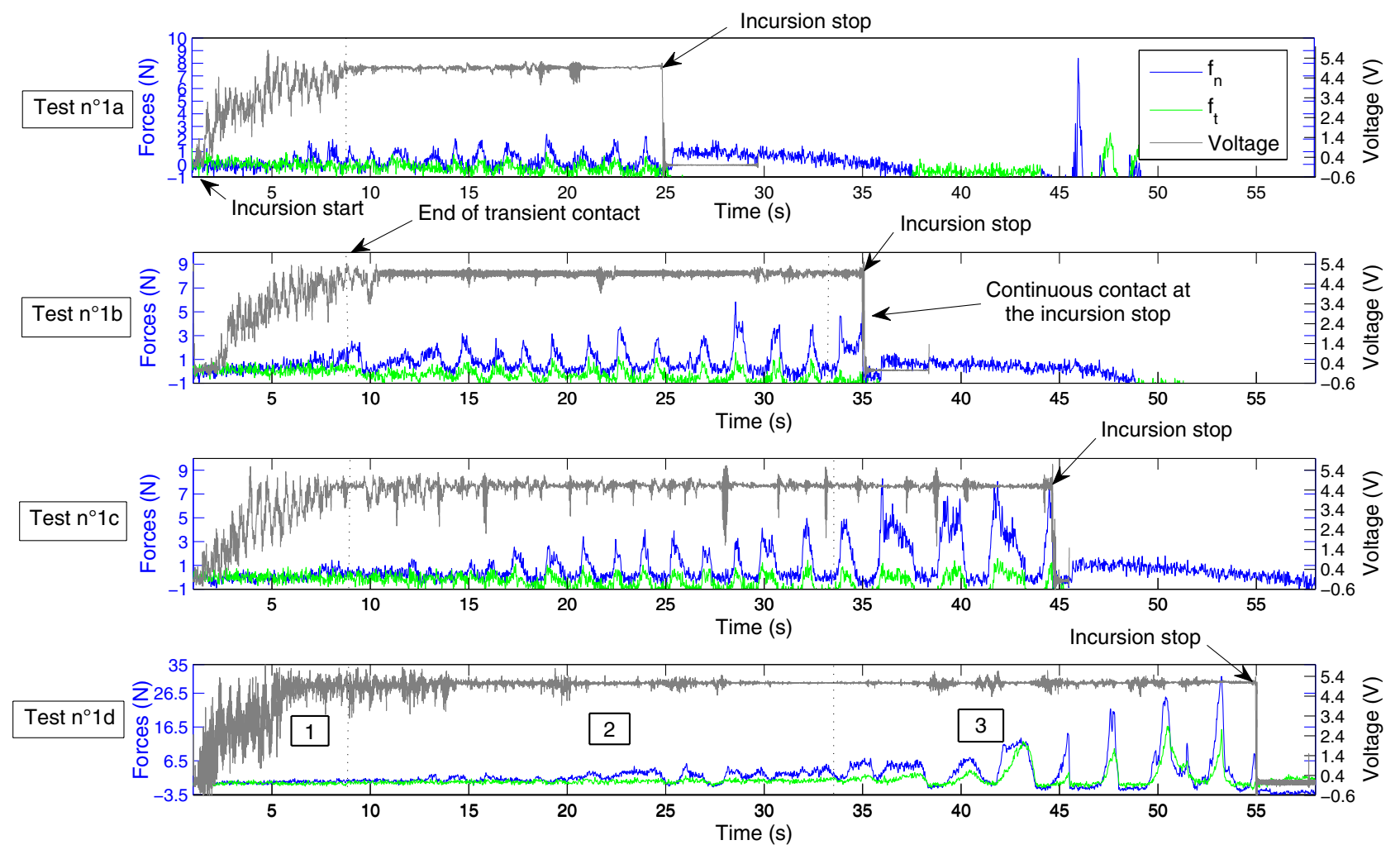

Fig. 9. The contact forces and voltage signals superimposition from test series No. $1\left(V_{r}=37500 \mathrm{rpm}, V_{\text {inc }}=0.005 \mathrm{~mm} . \mathrm{s}^{-1}\right)$.

cursion depth effect on the Al-Si 6\% abradable coating behavior, by carrying out post test analysis. The general test matrix of the study is given in Table 3 .

\section{Results and discussions}

\subsection{Interaction signals analysis}

The Al-Si $6 \%$ abradable coating behavior, depending on the incursion depth, is first studied by a recorded signals analysis from the different sensors fitted on the test rig. Figure 9 shows the forces (normal and tangential components) and the voltage signals from the test series No. 1 superimposed in the increasing incursion depth order as time function. This superimposition reveals a satisfactory repeatability in terms of the interaction forces. The force curve profiles and associated cyclic variations for each test are very similar and progress in an increasing way in response of the incursion depth increase. From these superimposition follows an interaction signal division composed of three distinct areas (Fig. 9, test No. 1d).

The first part (No. 1) is composed of a transient contact period between the labyrinth seal and the Al-Si $6 \%$ abradable coating, identified using the voltage signal and fixed approximately to $8.5 \mathrm{~s}\left(D_{p}=40 \mu \mathrm{m}\right)$. The transient contact period corresponds to the contact accommodation produced by the labyrinth seal geometric defects, the rotor unbalance and the Al-Si $6 \%$ surface finish. The second part (No. 2) is composed of the interaction test steady state operation, characterized by a voltage signal stabilization (distinct contact) and by contact forces variations with similar profiles. A single contact forces variation is composed of a fast increase up to a maximum followed by a decrease generating contact instabilities between the labyrinth seal tooth and the Al-Si $6 \%$ abradable coating 


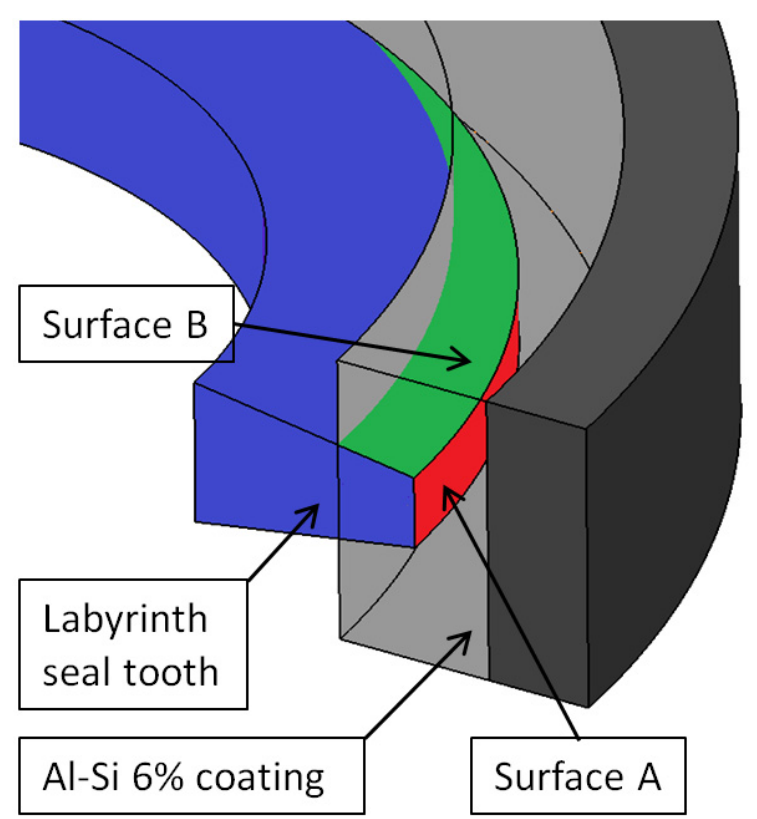

(a)

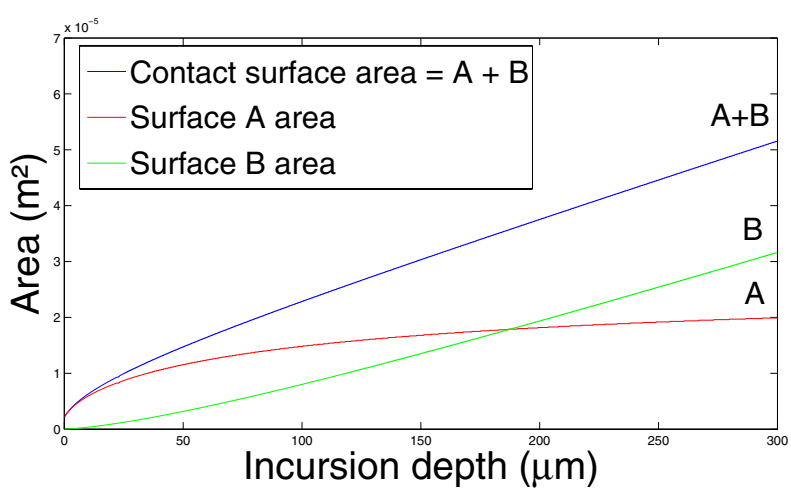

(b)

Fig. 10. (a) Tooth contact surfaces designation, (b) Tooth contact surfaces evolution depending on the incursion depth.

(Fig. 9). The contact instability is created by a mechanical clearance between the labyrinth seal tooth and the coating. The incursion test steady state operation is then composed of successives contact instabilities which appear between contact forces variations. Finally, the third part (No. 3) reveals a significant increase of contact forces amplitudes.

The interaction status at the end of the third part (between a contact force), corresponding to the labyrinth seal incursion depth stop, defines the final Al-Si 6\% rub-groove statement (surface roughness, rub-groove depth etc.). The final rub-groove statement will determine the Al-Si $6 \%$ behavior when it is subjected to additional and deeper labyrinth seal tooth incursions encountered in the turboengine lifetime. The final rub-groove statement from the test series No. 1 depending on the incursion depth is studied in Section 3.3.

The complex contact geometry induced by the incursion of a trapezoidal section of a circular tooth in a tube, necessarily has a significant impact on the signal shape which composed the three parts of the interaction signals. Figures 10a and10b presents the tooth contact surface area evolution during an incursion of $300 \mu \mathrm{m}$ depth. It is calculated using a CAD model and is based on the theoretical intersection of the labyrinth seal tooth and Al-Si $6 \%$ surface. The surface A, corresponding to the labyrinth seal tooth bottom area, progresses following a logarithmic function compared to the surface B (trapezoidal tooth edges) which progress according to a power function. The surface A contact area evolution seems to be the most influencing contact area at the beginning of the interaction (part Nos. 1 and 2). Once a certain incursion depth (part No. 3), the surface B contact area evolution seems to affect the contact forces evolution and in particular the tangential forces $f_{t}$.

Figure 11 shows the shear strain applied on the AlSi $6 \%$ coating and the temperature rise during the test No. 1d. The shear strain (Eq. (2)) highlights an important gap between the parts Nos. 2 and 3 corresponding to a temperature increase of $65{ }^{\circ} \mathrm{C}$. The average shear strain applied on the Al-Si $6 \%$ during the part Nos. 1 and 2 is equal to $0.78 \mathrm{MPa}$ compared to $2.47 \mathrm{MPa}$ in part No. 3 . The shear strain gap can be explained by an important increase of the coating temperature and thus to the friction forces. These observations reflect the appearance of a behavior change of the Al-Si $6 \%$ coating defined by a significant rise of the tangential forces $f_{t}$.

$$
\tau(t)=\frac{\left\|\overrightarrow{F_{t}(t)}\right\|}{S_{t}(t)}
$$

Concerning the test series No. 2, the contact forces superimposition reveals a good contact forces test repeatability (Fig. 12).

In fact, the normal $f_{n}$ and tangential $f_{t}$ forces of each test progress in a similar way depending on the incursion depth and are composed of a very fast maximum rise time and of a drop in the force, which corresponds to the cessation of the labyrinth seal incursion. A noticeable difference between $f_{n}$ curves slopes is observed and can be explained by a slight difference of the labyrinth seal dynamic according to the machine tool capabilities (see Sect. 2.3). The interaction forces signals from test series No. 2 can be divided in two distinct areas. The first (part Nos. 1 and 2) is composed of a simultaneous increase of $f_{n}$ and $f_{t}$ until a maximum value for each component. The linear increase of forces signals in part No. 1 is disrupted 


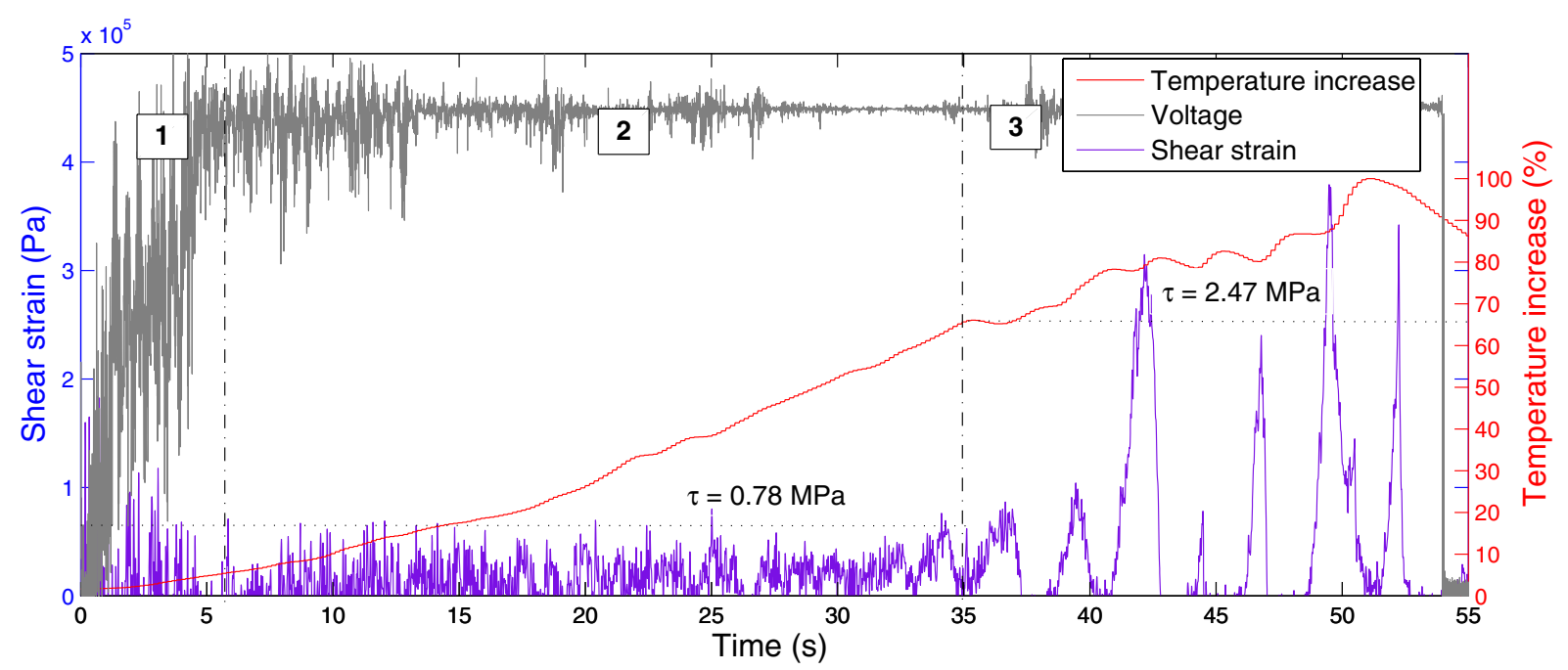

Fig. 11. Shear strain exerted on the Al-Si $6 \%$ and the temperature evolution from test No. $1 \mathrm{~d}\left(V_{r}=37500 \mathrm{rpm}, V_{\text {inc }}=\right.$ $0.005 \mathrm{~mm} . \mathrm{s}^{-1}, D_{p}=265 \mu \mathrm{m}$.

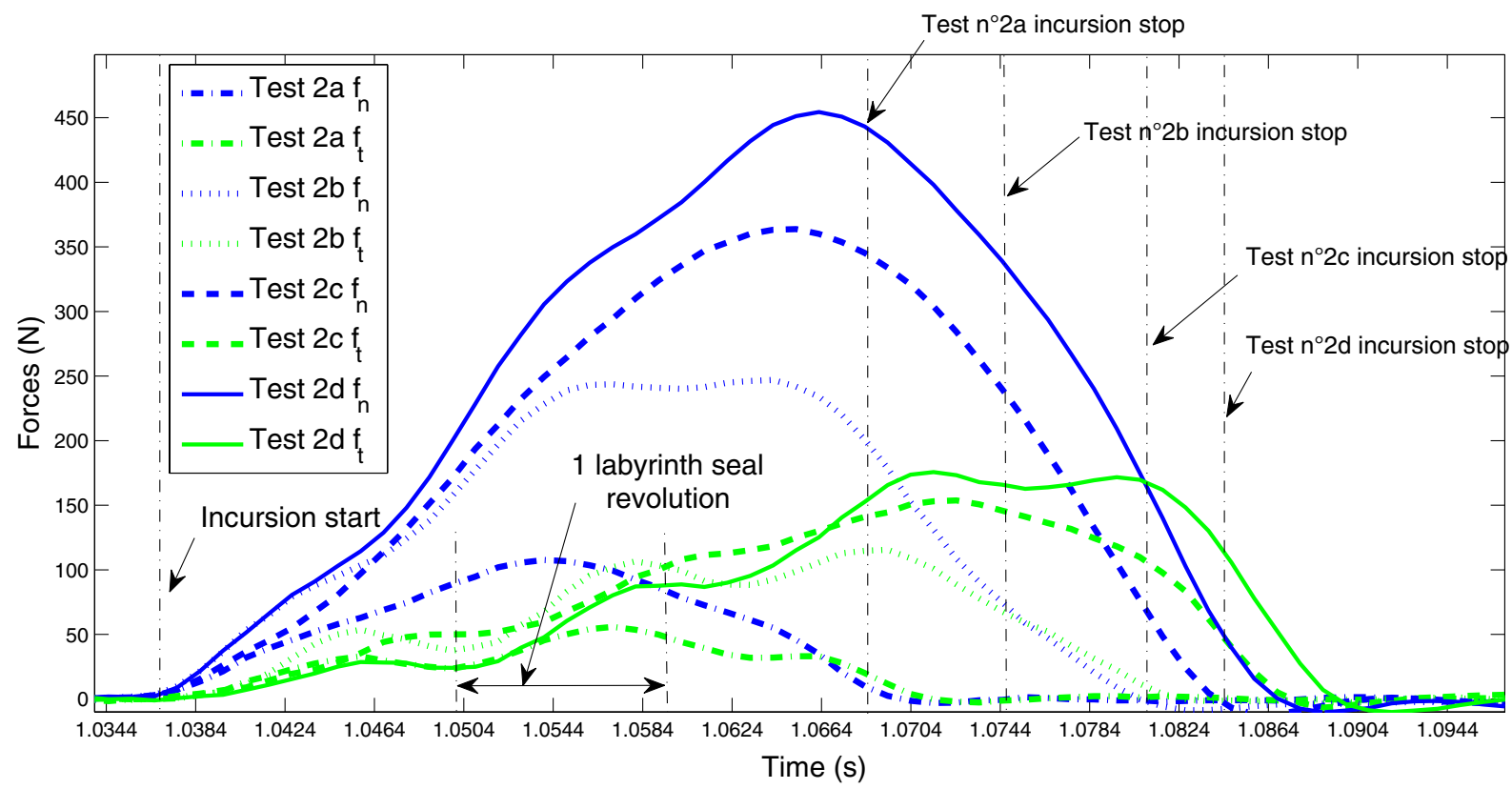

Fig. 12. Contact forces signals superimposition from test series No. $2\left(V_{r}=5000 \mathrm{rpm}, V_{\text {inc }}=9.41 \mathrm{~mm} . \mathrm{s}^{-1}\right)$.

by a periodic phenomenon which appears approximately after one labyrinth seal revolution and with a frequency of $80 \mathrm{~Hz}$ that is close to the test series No. 2 rotational frequency $f_{r 2}$. This periodic phenomenon is identified as a specific Al-Si $6 \%$ behavior, contrary to a rotor unbalance effect. The repeatable characteristic of this period on the test series No. 2 confirmed an impacting phenomenon of the Al-Si $6 \%$ behavior. The second area (part Nos. 3 ans 4 ) is then characterized by a decrease of the normal force $f_{n}$ while the tangential force $f_{t}$ is kept constant during one labyrinth seal revolution, and finally decrease until the end of the labyrinth seal tooth incursion.

Figures 13 and 14 show the shear strain applied on the Al-Si $6 \%$, and the friction coefficient evolution during test No. 2d. The shear strain evolution highlights four significant divisions of one labyrinth seal rotation wide. The significant increase of the friction coefficient from part Nos. 3 and 4 (probably induced by a temperature increase) shows the significant appearance of a different Al-Si $6 \%$ coating behavior.

A first low frequency understanding of the test series No. 1 \& 2 have been performed using the contact forces and thermocouple signals. A better understanding of the Al-Si $6 \%$ behavior could be provided by a high frequency analysis of the accelerometer and the acoustic emission signals recorded during the contact interaction. The fast Fourier transform (FFT) and the associated short-time Fourier transform (STFT) are commonly used to identify 


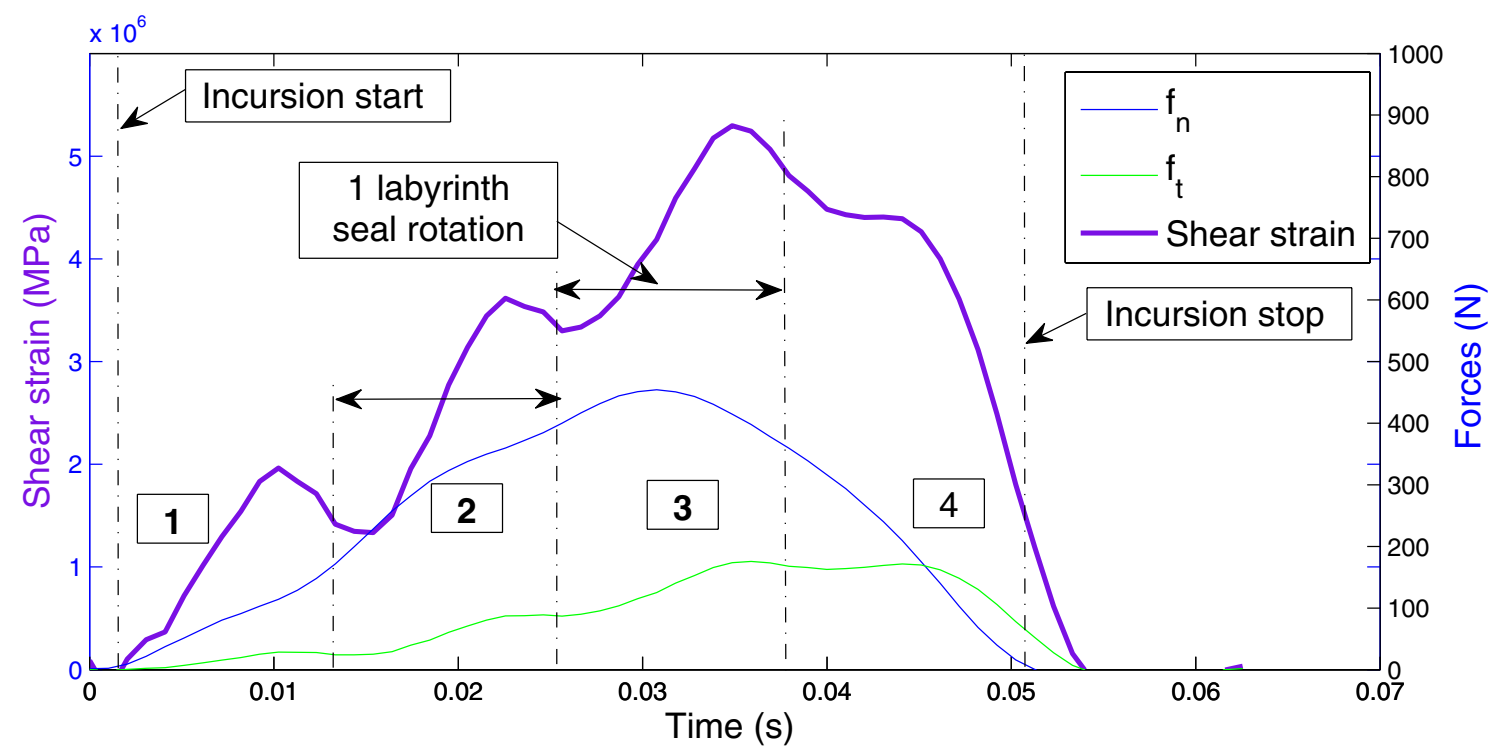

Fig. 13. Shear strain exerted on the Al-Si $6 \%$ and the contact forces signals from test No. $2 \mathrm{~d}\left(V_{r}=5000 \mathrm{rpm}, V_{\text {inc }}=\right.$ $\left.9.41 \mathrm{~mm} . \mathrm{s}^{-1}, D_{p}=229 \mu \mathrm{m}\right)$.

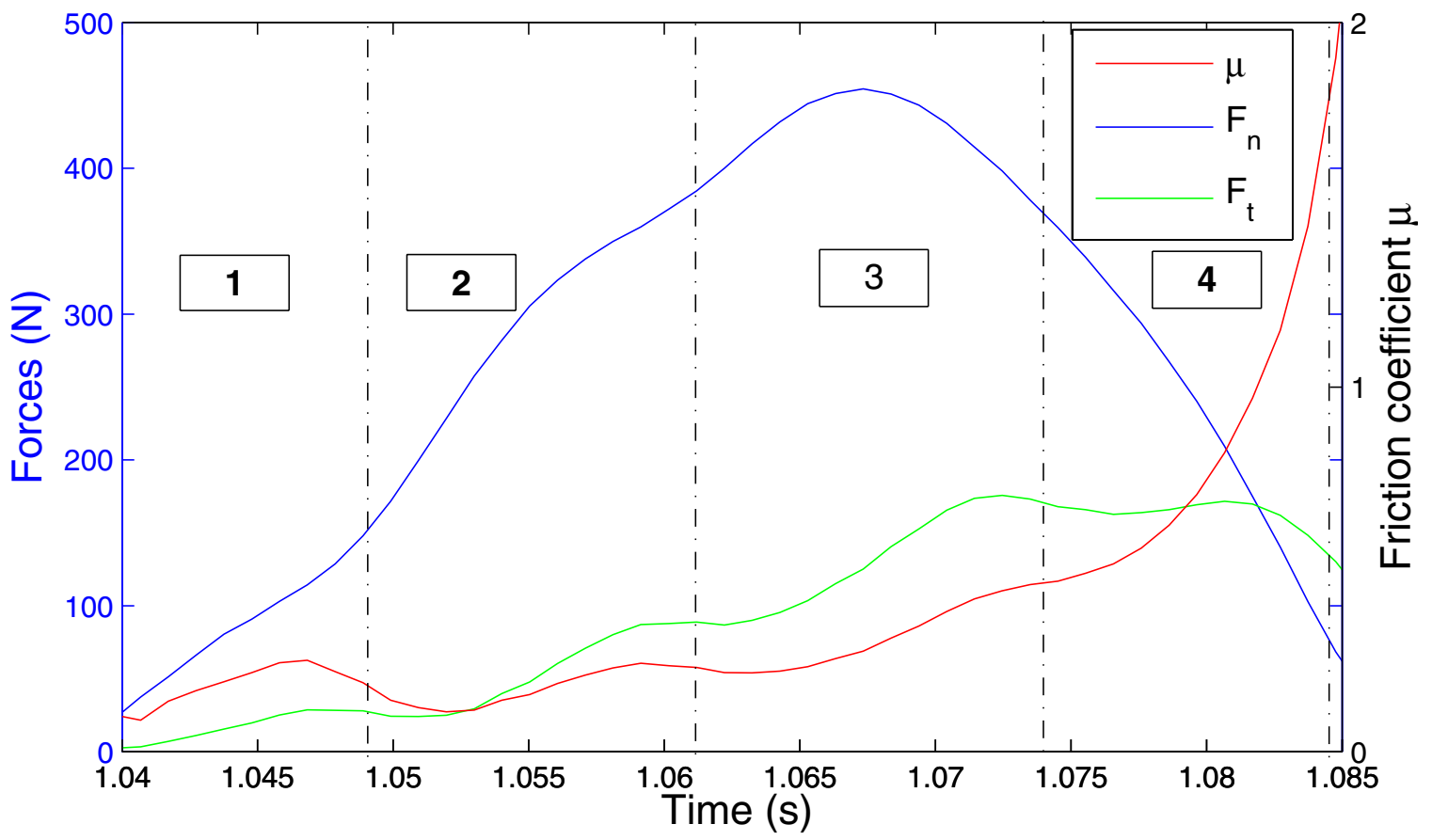

Fig. 14. Friction coefficient and the contact forces signals from test No. $2 \mathrm{~d}\left(V_{r}=5000 \mathrm{rpm}, V_{i n c}=9.41 \mathrm{~mm} . \mathrm{s}^{-1}, D_{p}=229 \mu \mathrm{m}\right)$

inside the acoustic emission signals, a frequency signature associated to a specific wear mechanism occurring during a contact interaction $[21,25]$.

\subsection{Time-frequency analysis}

Test Nos. 1d and 2d represent the overall incursion depth evolution during the interaction (from 0 to $265 \mu \mathrm{m}$ for the test series No. 1 and from 0 to $229 \mu \mathrm{m}$ for the test series No. 2). Figure 15 shows the accelerometer signal fast Fourier transform (FFT) fitted on the housing support during the interaction. The rotational frequency $f r_{1}$ is identified on the frequency spectrum at $625 \mathrm{~Hz}$, as well as its corresponding harmonics and subharmonics. A higher vibration activity is identified around $7 \times f r_{1}$. The $f r_{1}$ harmonics excitement are to be expected, but it demonstrates that the vibration activity is mainly composed of forced vibrations induced by the labyrinth seal tooth rotation and the rotor unbalance. Nevertheless, the harmonics and especially the sub-harmonics may translate non-linear wear phenomena in the Al-Si 6\% 


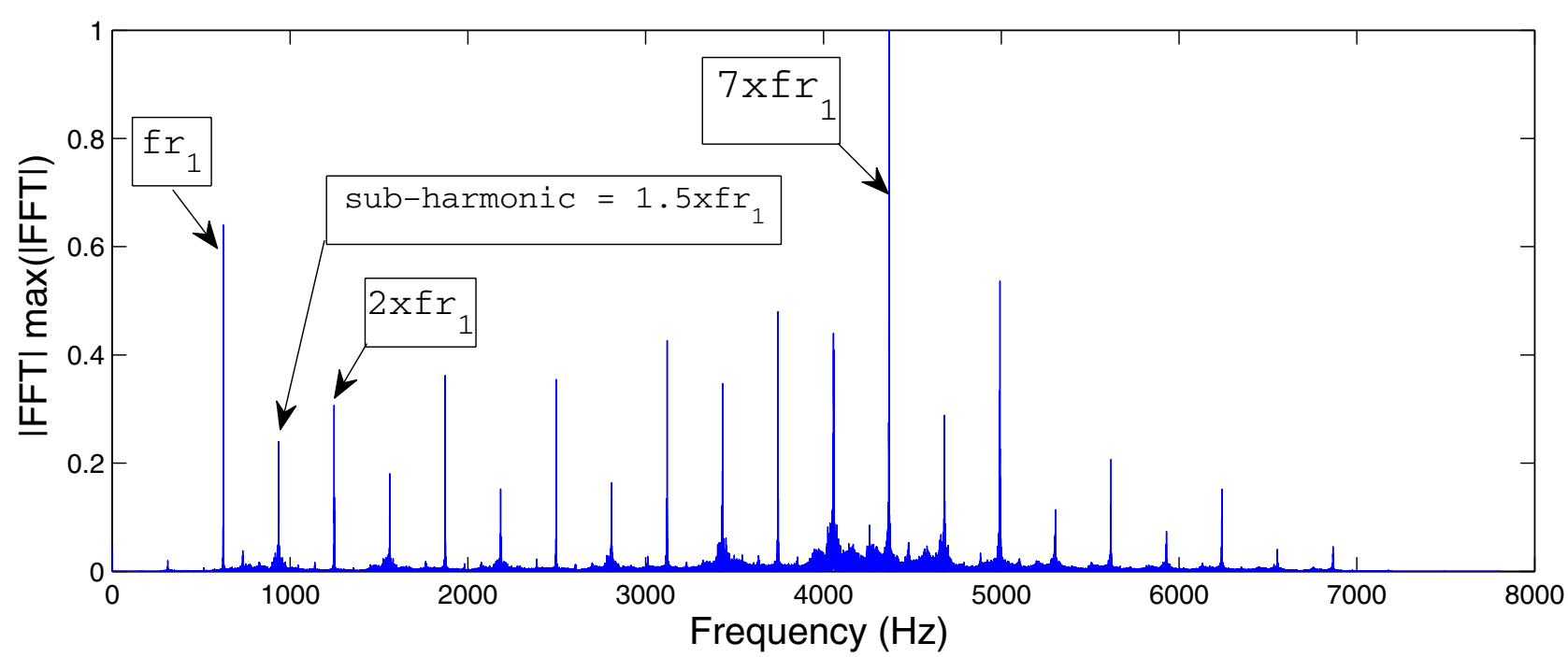

Fig. 15. FFT spectrum of the accelerometer signal from test No. 1d.

behavior during the interaction that is left to be characterized. A time-frequency analysis, which is not presented in this study, reveals that the frequency spectrum doesn't progress during the contact interaction. The three different parts which constitute the temporal signal from the contact forces measurement previously describe in Section 3.1 are not identifiable in the vibration timefrequency domain. Nevertheless, the frequency spectrum constitutes the housing support vibrations frequency signature subjected to a labyrinth seal tooth incursion in No. 1 condition No. 1. Due to a sensor saturation during the test No. 2d, cause by the high incursion speed $V_{\text {inc }}$ (similar to a shock), the signal was not analyzed.

Concerning the acoustic emission signals, a simple fast Fourier transform was not entirely adapted to fully characterized the signals. Employed an adapted time-frequency tool as the short-time Fourier transform (STFT) on the acoustic emission signals, correspond to determine the AE frequency spectrum temporal distribution during the labyrinth seal tooth incursion, that is not possible with a global FFT representation. The STFT corresponds to a FFT that is applied over a sweep signal window. The length of the window determines the timefrequency resolution. The STFT of a signal $x(t)$ can be expressed by,

$$
w(t, \omega)=\frac{1}{\sqrt{2 \pi}} \int \exp ^{-j \omega \tau} x(\tau) h(\tau-t) \mathrm{d} \tau
$$

where $h(t)$ is a window function centered at time $t$.

Figure 16 presents a time-frequency analysis of the AE signal from the test No. 1d (frame (A)). The STFT results are plotted using a spectrogram which is a visual representation of the frequency spectrum as they vary with time along the $y$ - and $x$-axis respectively (frame $(\mathrm{C})$ ). All the three frames share the same time axis, while the STFT and FFT share the same frequency axis. The resulting transform modulus is depicted using a color map in a decibel scale. The STFT was computed using Equation (3) and a Blackman window of 60 labyrinth seal rotations wide (corresponding to temporal duration of $96 \mathrm{~ms}$ wide) and no overlapping. In the interest of the calculation time and efficiency, the signal is sub-sampled at a sampling frequency of $250 \mathrm{kHz}$. The frame (B) in Figure 16, corresponding to the temporal signal FFT, is mainly composed of a frequency band from $13 \mathrm{kHz}$ to $40 \mathrm{kHz}$. This frequency band corresponds to the major AE events frequencies and constitutes the test No. 1d AE frequency signature. The transient part 1 described in the previous section, is identified by a low frequency band modulus. No particular frequency was identified to characterized the signal differentiation in the parts Nos. 2 and 3 at a sampling frequency of $250 \mathrm{kHz}$.

Nevertheless, Figure 17 (frame $(\mathrm{C})$ ) shows the timefrequency analysis of the AE signal from test No. $2 \mathrm{~d}$ at a sampling frequency of $1 \mathrm{MHz}$, and reveals a significant different temporal distribution of frequencies which composed the FFT spectrum (frame (B)) during the interaction. The temporal signal (frame (A)) and the STFT (frame (C)) reinforce, according to the shear strain signal (Fig. 13), the four parts signal division and combining their own frequency signatures. Parts Nos. 1 and 2 are mainly composed of a frequency band from $13 \mathrm{kHz}$ and $42 \mathrm{kHz}$, which is similar to the frequency band observed in the test No. 1d. The part No. 3 is characterized by the frequency appearance $f_{2}=428 \mathrm{kHz}$ with a high power spectral density. The $f_{2}$ frequency disappears in the part No. 4 characterized by a central frequency $f_{3}=204 \mathrm{kHz}$ and a general frequencies modulus raising. Finally, the part No. 5 can be associated to the gradually labyrinth seal incursion stop. In agreement with the correlation between the acoustic emission signals features and the mechanical wear mechanisms experiments conducted by Hase et al. [21], the acoustic emission frequency signatures associated to the distinct signals division parts can correspond to particular wear mechanisms. The similar frequency bands from both test conditions may be associated to the abrasive wear mechanism which mainly 

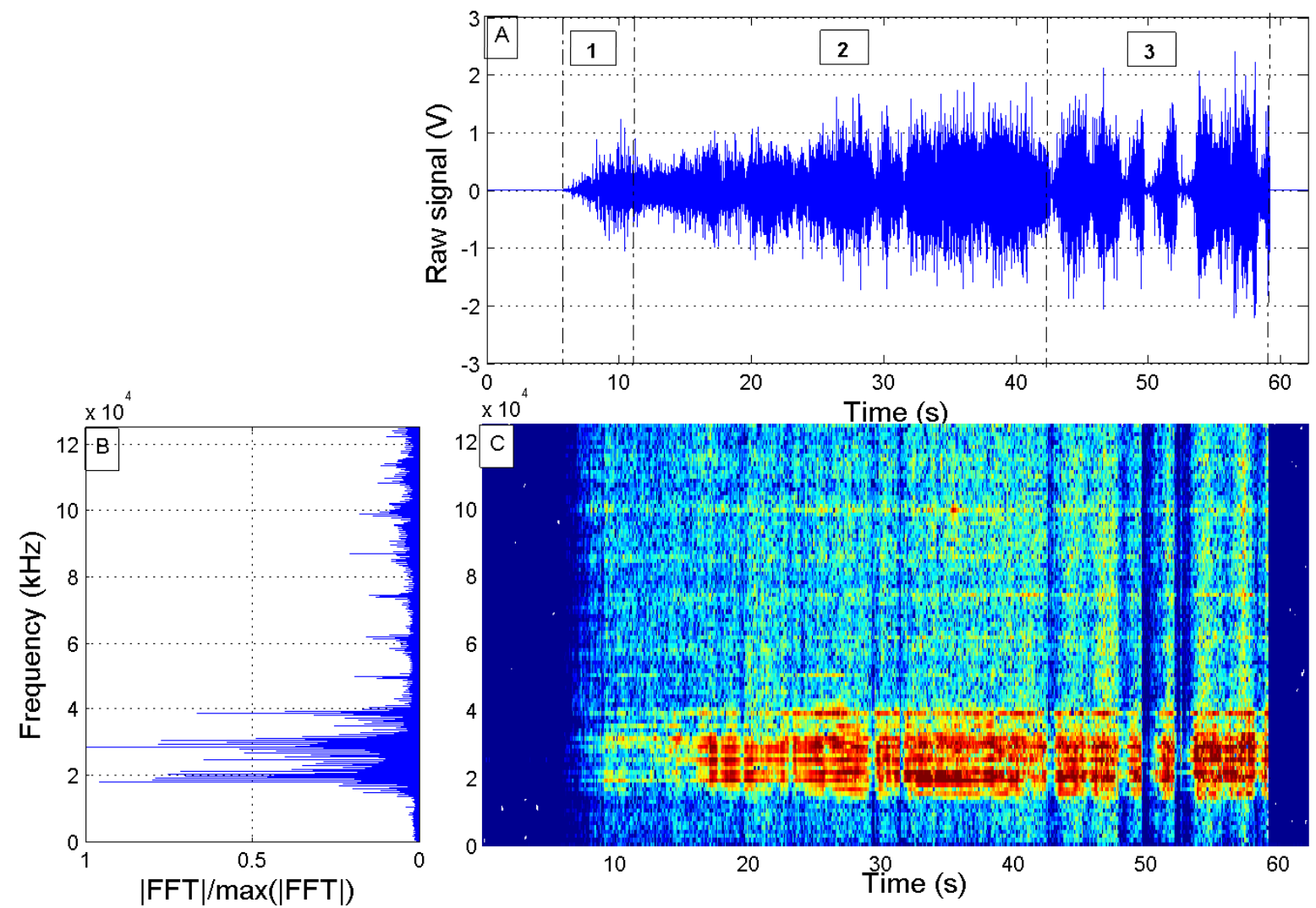

Fig. 16. Time-frequency analysis of the AE signal from test No. 1d: (A) AE temporal signal, (B) FFT modulus of AE signal, (C) STFT of AE signal
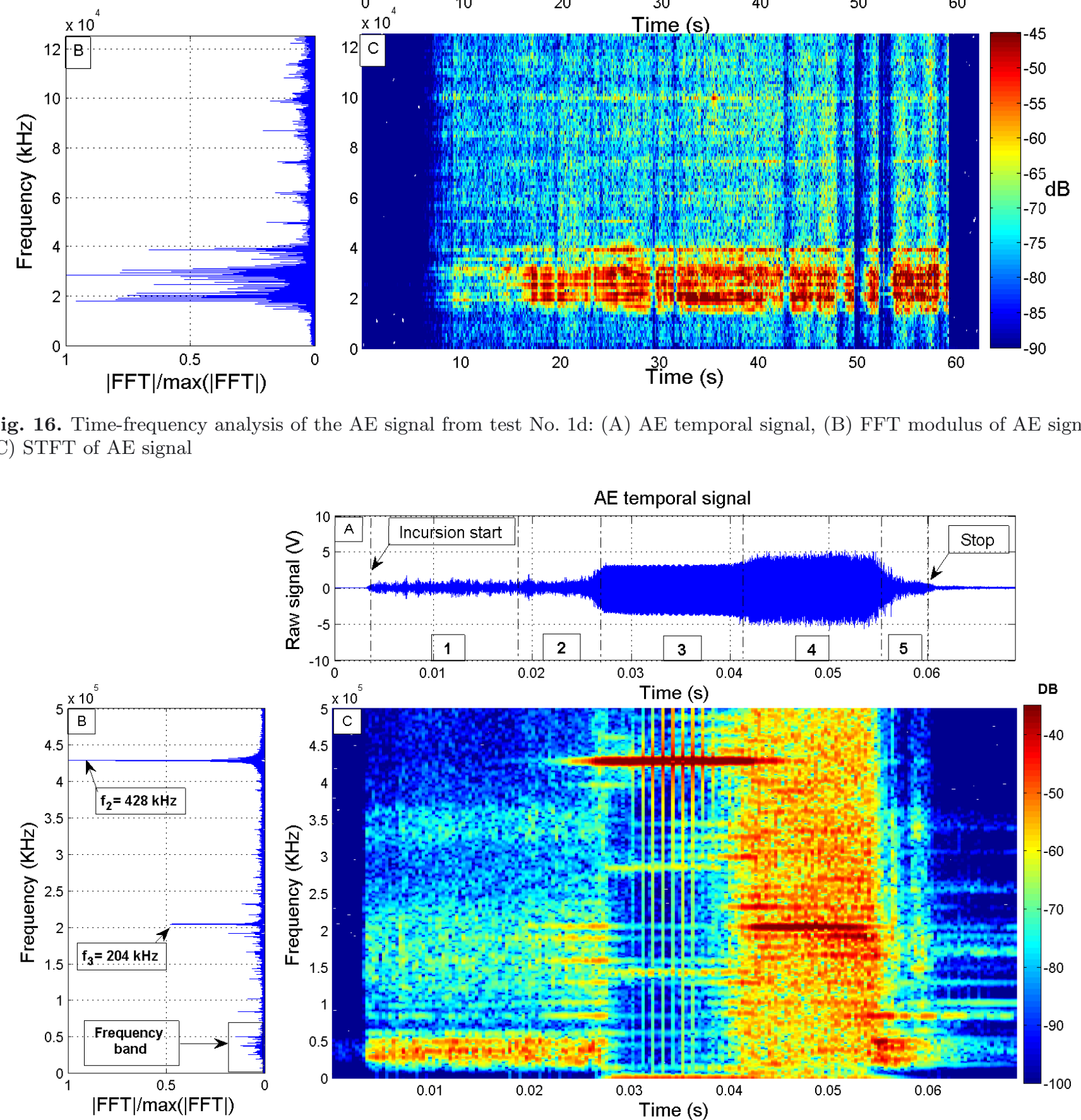

Fig. 17. Time-frequency signal from test No. 2d analysis: (A) AE temporal signal, (B) FFT modulus of AE signal, (C) STFT of AE signal. 

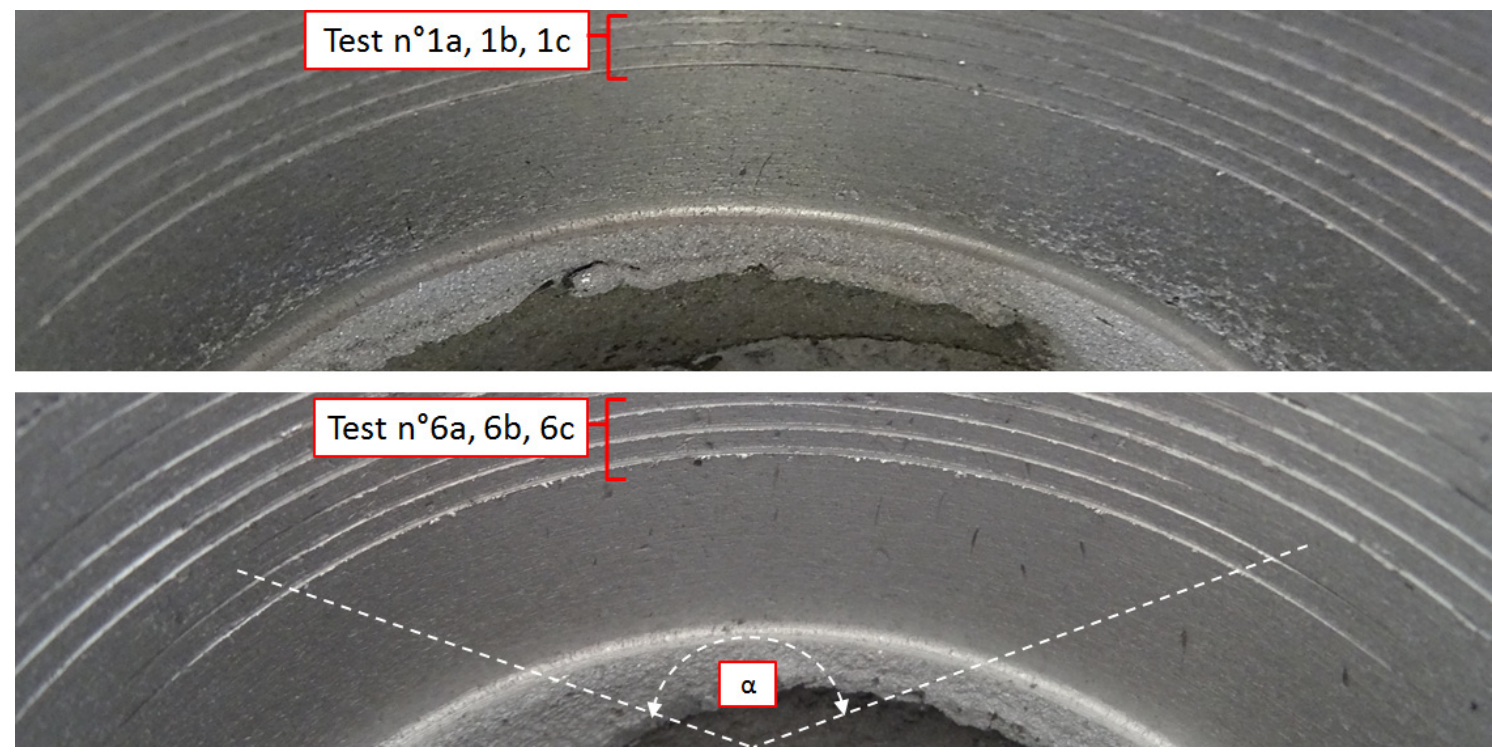

Fig. 18. Images of the abradable rub-grooves after test Nos. 1a, 1b, 1c and $6 \mathrm{a}, 6 \mathrm{~b}$ and $6 \mathrm{c}$.

composed the test series No. 1. the particular frequency as $f_{2}$ and $f_{3}$ may be associated to a severe wear, or a severe defect propagation in the Al-Si $6 \%$ coating.

\subsection{Al-Si $6 \%$ worn surfaces characterizations}

To complete the Al-Si $6 \%$ abradable coating behavior study and the interaction signals analysis, macrographic examinations has been initially performed on the contact protagonists after the tests and especially on the rubgroove left by the labyrinth seal tooth incursion on the Al-Si $6 \%$ coating surface.

Figure 18 presents six rub-grooves on two abradable samples among others and corresponding to the incursion tests Nos. 1a, 1b, 1c, 2a, 2b and 2c. As described theoretically in Section 2.1, the contact angular length $\alpha$ evolves gradually depending on the incursion depth but is not quantified in this study. A first assessment of the high-speed contact interaction was conducted in a previous study [20] by an analysis of test samples, visual rubgroove observations and accurate profile measurements which revealed different material deformation and wear phenomena. In this study, the wear dynamic is described by considering a third body approach defined as an integral part of the three level tribological sub-system (triplet tribological [26]). In this approach, the first bodies are identified as the labyrinth seal tooth and the Al-Si $6 \%$ abradable coating. The third body is defined as a dynamic interface element such as detached particles, debrus (omnipresent in the relevant contact) separating the contacting surfaces, which actes as an intermediate screen and is able to support the major part of the speed difference between the contact first bodies.

Figure 19 presents in front view the rub-grooves from test Nos. 1d and 2d on the Al-Si 6\% surface, focused on the half-section rub-groove and divided in four different observation sectors. The first sector corresponds to the location where the incursion depth of the labyrinth tooth in the Al-Si $6 \%$ coating is the greatest, while the sector 4 corresponds to the lower incursion depth. From these test Nos. $1 \mathrm{~d}$ and $2 \mathrm{~d}$ rub-grooves examinations, appears that the Al-Si $6 \%$ surface is mainly damaged by an abrasive wear mechanism encountered in both contact conditions. It is characterized by a high amount of fine powder particles ejection, in a pulverulent form and relatively not cohesive, thus providing a first type of third body. The powder located inside the housing support after tests has not been investigated in this study.

In addition, a large plastic deformation is observed and characterized by a large amount of plastically deformed coating on both sides of the rub-groove as a result of the high Al-Si 6\% ductility. A specific adhering layer is identified in the rub-groove bottom (smooth and cohesive) and is defined as a second third body type generated at the labyrinth seal and Al-Si $6 \%$ coating interface. The third body generates a cohesive tribofilm composed of detached elements from both two first bodies and give rise to a transfer layer. Finally, an interface becomes the third body layer composed of detached interfacial elements (first bodies elements) separating the contacting surfaces. An interface crack between the third body and the Al-Si $6 \%$ abradable coating is observed on the SEM image from test No. $2 \mathrm{~d}$ (sector 2). It is demonstrated that the thermal and transverse cracks may impact the third body and generate a partial or a complete tribofilm detachment.

A rub-groove EDX analysis have been performed to identify the layer chemical composition. It mainly reveals the presence of aluminium and silicon (the Al-Si $6 \%$ abradable coating main additives), except for the test No. 1d where the presence of chrome (the stainless steel $\mathrm{X} 5 \mathrm{CrNiCuNb}$ 17-04 main additive) has been identify and seems to come from the labyrinth seal tooth. The labyrinth seal material transfer is perceptible on the test 


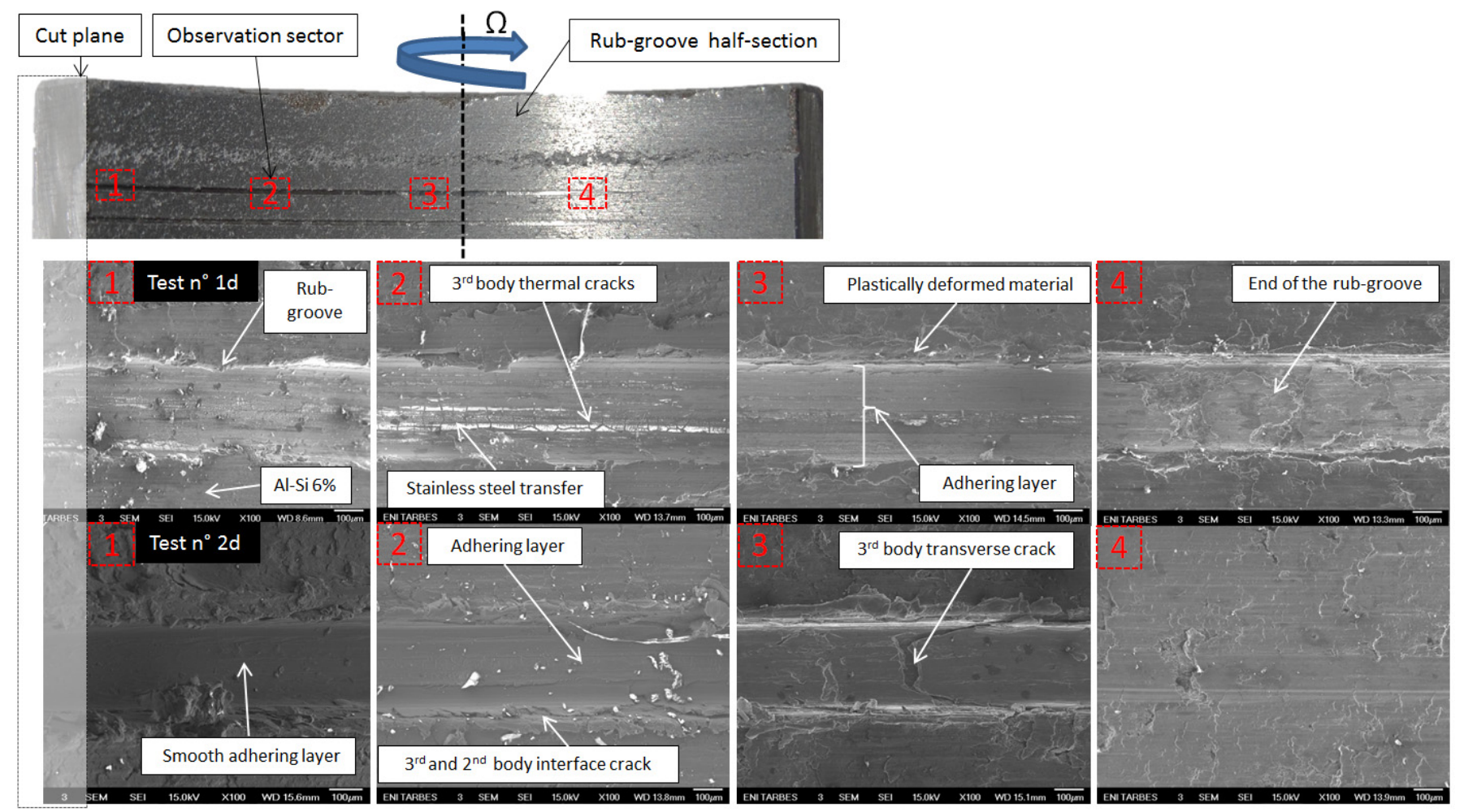

Fig. 19. SEM images in front view of four different observation sectors of the rub-groove on the Al-Si $6 \%$ surface from tests Nos. $1 \mathrm{~d}$ and $2 \mathrm{c}$.

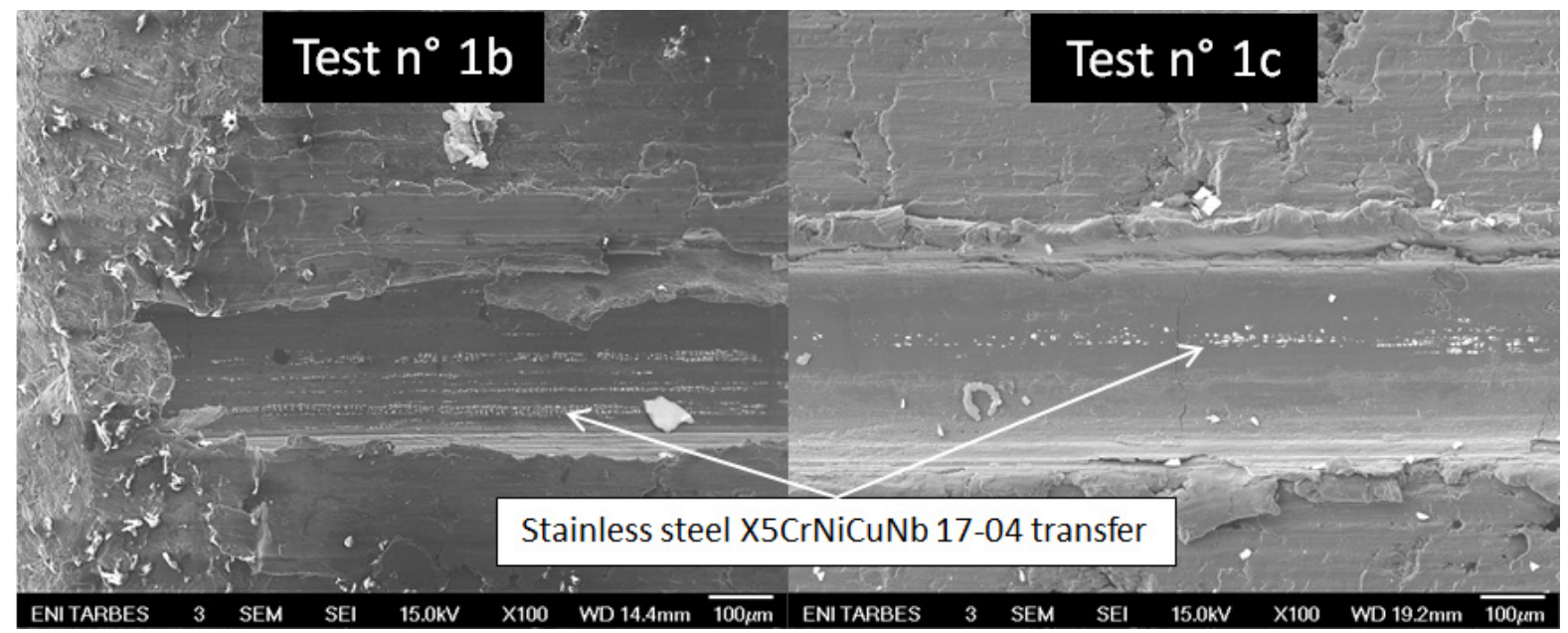

Fig. 20. Stainless steel $\mathrm{X} 5 \mathrm{CrNiCuNb} 17-04$ transfer in the third body from tests Nos. $1 \mathrm{~b}$ and 1c.

Nos. 1b and 1c in a lower amount (Fig. 20) and not in the test No. 1a. According to the test No. 1d signal analysis in Section 3.1, the material transfer can be associated to the signal part No. 3 defined previously, and occurs at a greater incursion depth than $160 \mu \mathrm{m}$. The presence of thermal cracks on the third body surface indicates a significant rise in the temperature (more than $65 \%$ of temperature increase) followed by a rapid cooling.

It is therefore interesting to identify the mechanism during contact instabilities by comparing the micrographic rub-grooves from different incursion stop conditions. Unfortunately, none of the test series No. 1 have been stopped in a discontinuous contact condition, which implied to simulate the test No. 1d until a satisfactory result was obtained. Figure 21 presents contact forces signal from additional test No. $1 \mathrm{~d} 2$ and a comparison of rubgroove morphologies from test No. 1b (continuous contact), test No. 1c (continuous contact close to the contact instability) and test No. 1d2 (contact instability). Further to rub-groove morphology of test No. 1d2, no adhering layer is observed on the rub-groove which highlights a third body shearing on the whole rub-groove, thereby leaving a deeper rub-groove made of raw Al-Si $6 \%$. The final rub-groove statement from the test series 

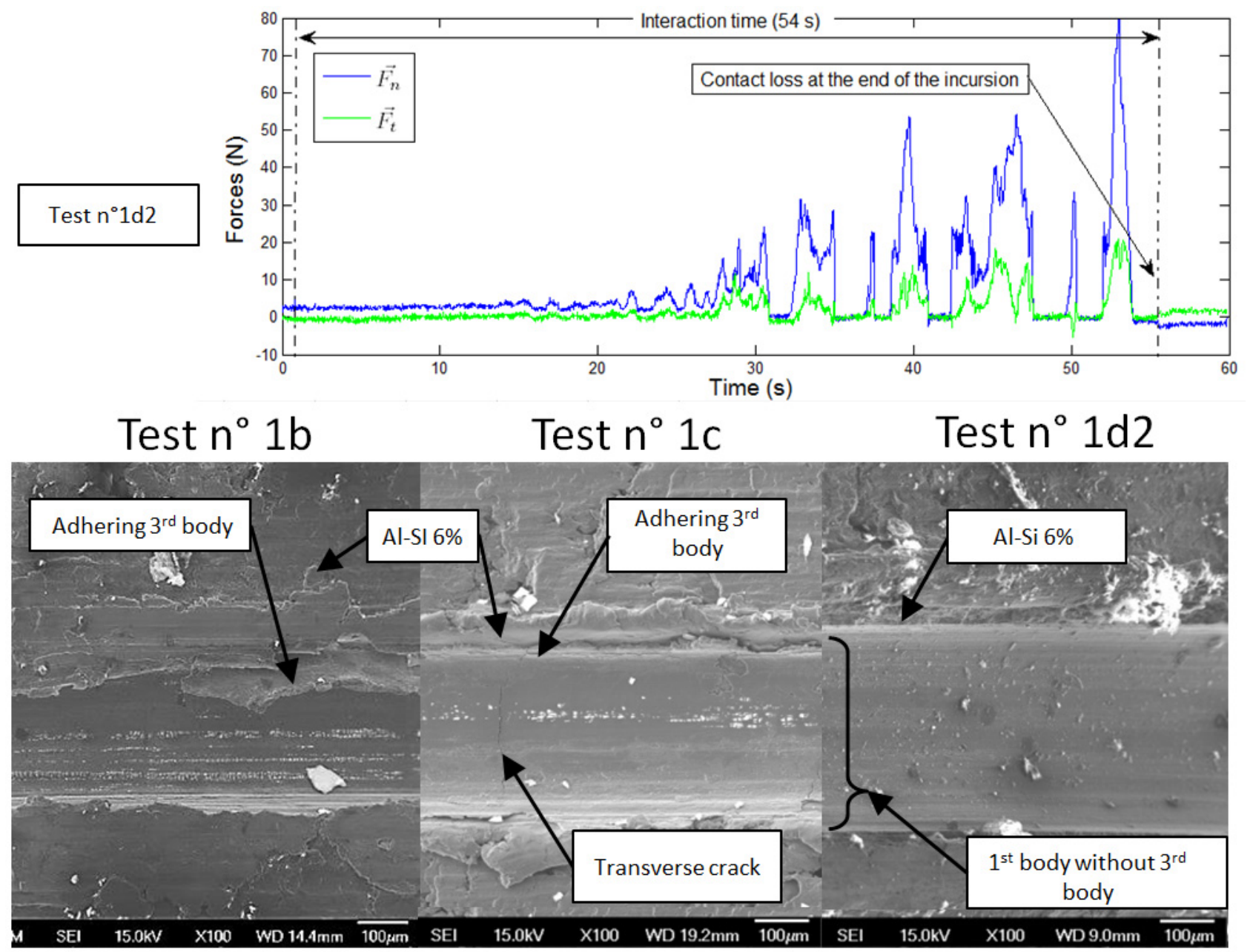

Fig. 21. Contact forces signals from test No. $1 \mathrm{~d} 2\left(V_{r}=37500 \mathrm{rpm}, V_{i n c}=9.41 \mathrm{~mm} . \mathrm{s}^{-1}, D_{p}=265 \mu \mathrm{m}\right)$ and comparison of the rub-groove morphologies from tests Nos. $1 \mathrm{~b}, 1 \mathrm{c}$ and $1 \mathrm{~d} 2$.

No. 1, depending on the incursion depth, depends on the incursion stop contact conditions and more globally of the third body life during the high speed contact interaction.

To complete the rub-grooves front view observations on the Al-Si $6 \%$ surface, microscopic examinations on cross-section views of the rub-grooves were performed on the Al-Si $6 \%$ abradable surface at the maximum incursion depth area. For that, the half section rub-groove in Figure 19 was cut up, embedded in a phenolic resin and polished using a $3 \mu \mathrm{m}$ diamond suspension.

Figure 22 presents a cross-section views of the rub-groove morphology from test No. 1c $\left(V_{r}=\right.$ $\left.37500 \mathrm{rpm}, V_{\text {inc }}=0.005 \mathrm{~mm} . \mathrm{s}^{-1}, D_{p}=215 \mu \mathrm{m}\right)$ and highlights the third body distribution around the rubgroove. Various third body thicknesses (thicker at the tooth center) reveal the existence of a material confinement phenomena, induced by the contact pressure caused by the labyrinth seal incursion. In addition, the second third body type ejection is identified as a deformation mechanism on both sides of the rub-groove at the origin of the amount of plastically deformed material ejected from the contact on the Al-Si $6 \%$ surface.
Additional microscopic examinations on cross-section views of the labyrinth seal tooth after test were performed on the unique labyrinth seal sample used on this study in order to superimpose the labyrinth seal tooth inside the rub-groove and highlight the contact evolution.

Figure 23 presents successive cross-section views of the labyrinth seal tooth inside the rub-groove at the maximal incursion depth from tests Nos. 1a, 1b, 1c and $1 \mathrm{~d}\left(V_{r}=\right.$ $\left.37500 \mathrm{rpm}, V_{i n c}=0.005 \mathrm{~mm} . \mathrm{s}^{-1}\right)$ and tests Nos. 2a, 2b, $2 \mathrm{c}$ and $2 \mathrm{~d}\left(V_{r}=5000 \mathrm{rpm}, V_{i n c}=9.41 \mathrm{~mm} . \mathrm{s}^{-1}\right)$ in respect of increasing incursion depths. This evolution quantitatively reflects that the Al-Si $6 \%$ wear and particularly the incursion depth $D_{p}$ into Al-Si $6 \%$ can be qualified as imposed by the labyrinth seal tooth. In fact, the rubgroove geometry on the Al-Si $6 \%$ abradable coating are very similar to the labyrinth seal tooth geometry, regardless the interaction test conditions. The Al-Si $6 \%$ behavior differences are then focused on the third body nature and its evolution, resulting of the interaction. It has been previously indicated, that the rub-groove surface roughness or chemical composition depends on the full life-cycle of the third body. Figure 24 presents the tribofilm thickness 


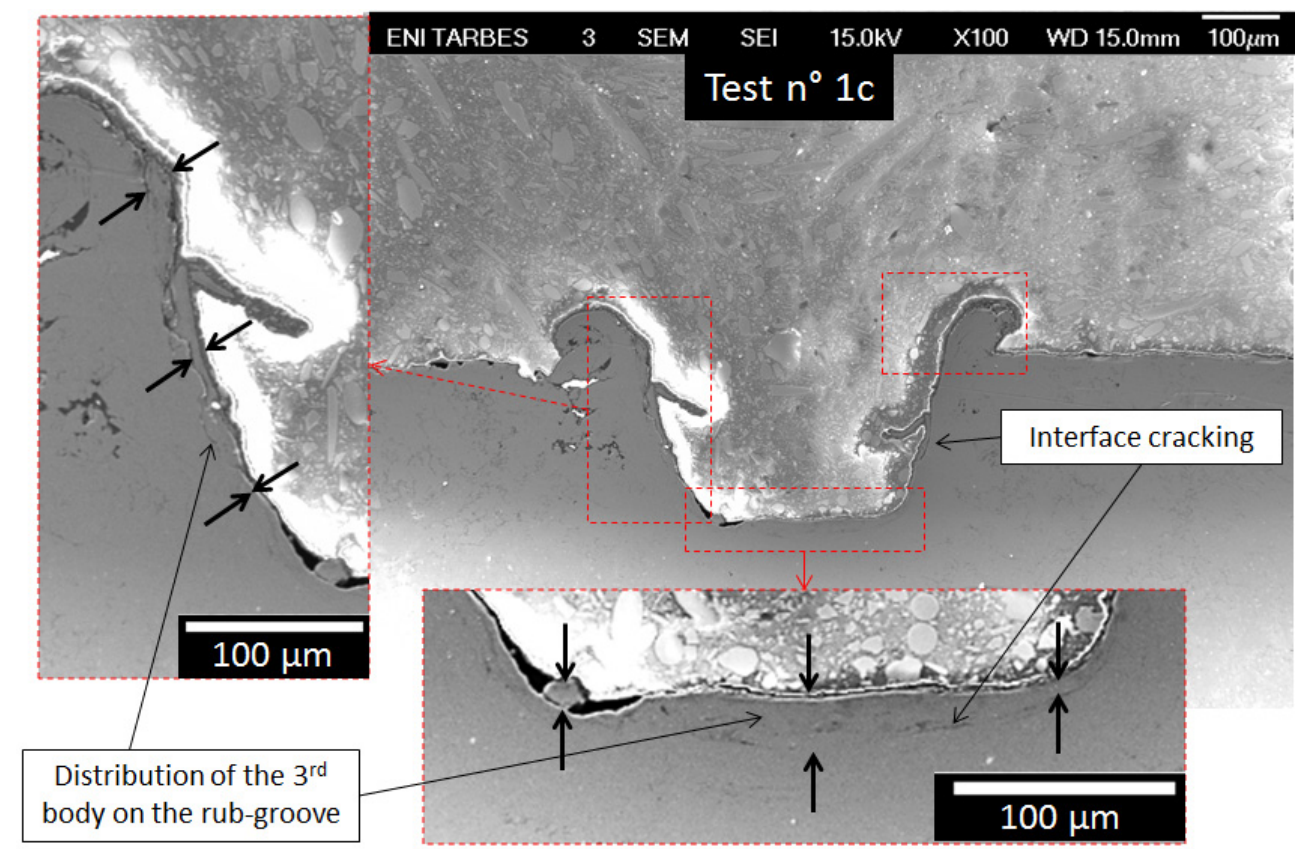

Fig. 22. Rub-groove morphology on a cross-section view focused on the third body distribution (SEM images from test No. 1c $\left(V_{r}=37500 \mathrm{rpm}, V_{i n c}=0.005 \mathrm{~mm} \cdot \mathrm{s}^{-1}, \mathrm{D}_{\mathrm{p}}=215 \mu \mathrm{m}\right)$.

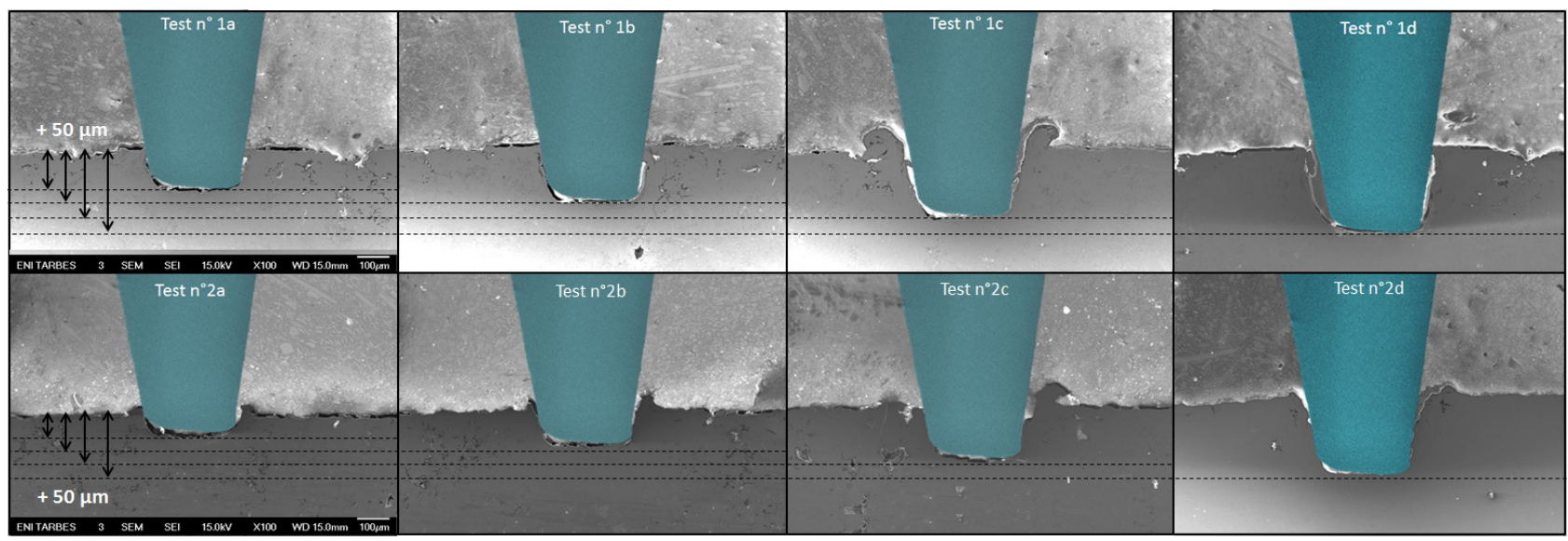

Fig. 23. SEM image on cross-section views of the labyrinth seal tooth inside the rub-grooves.

evolution as a function of the test series conditions and the incursion depth $D_{p}$ and highlights that such thickness depends on the incursion depth. It is indeed necessary to estimate the full-life contact scenario by considering the role of the both first bodies and third body according to the creation of debris, the material flow direction, and the ejection out of the friction rub-grooves.

The role of the contact confinement and the possibility of a chemical reaction with the oxygen may explain these two kind of particles production. In this approach, the tribological cycle deals with the different material flow create during the contact: two distinct material flows operate in this case are identified:

- a very majority longitudinal flow (in the direction of the labyrinth seal tooth rotation) and characterized by a low third body confinement referred to as a high speed ejection out of the contact. This longitudinal flow is generated by the abrasion wear mechanism.

- a minority transverse flow (perpendicular to the rubgroove direction) characterized by a high material confinement and controlled by the incursion depth of the tooth. It is generated by an adhesive wear mechanism without support of oxygen. The ejection of this adhering and ductile layer is observed by a large amount of plastically deformed material on both sides of the rub-groove as a result of free-surface creation at the tooth end.

\section{Conclusions}

In this study, the high speed interactions between an Al-Si 6\% abradable coating and a stainless steel labyrinth 


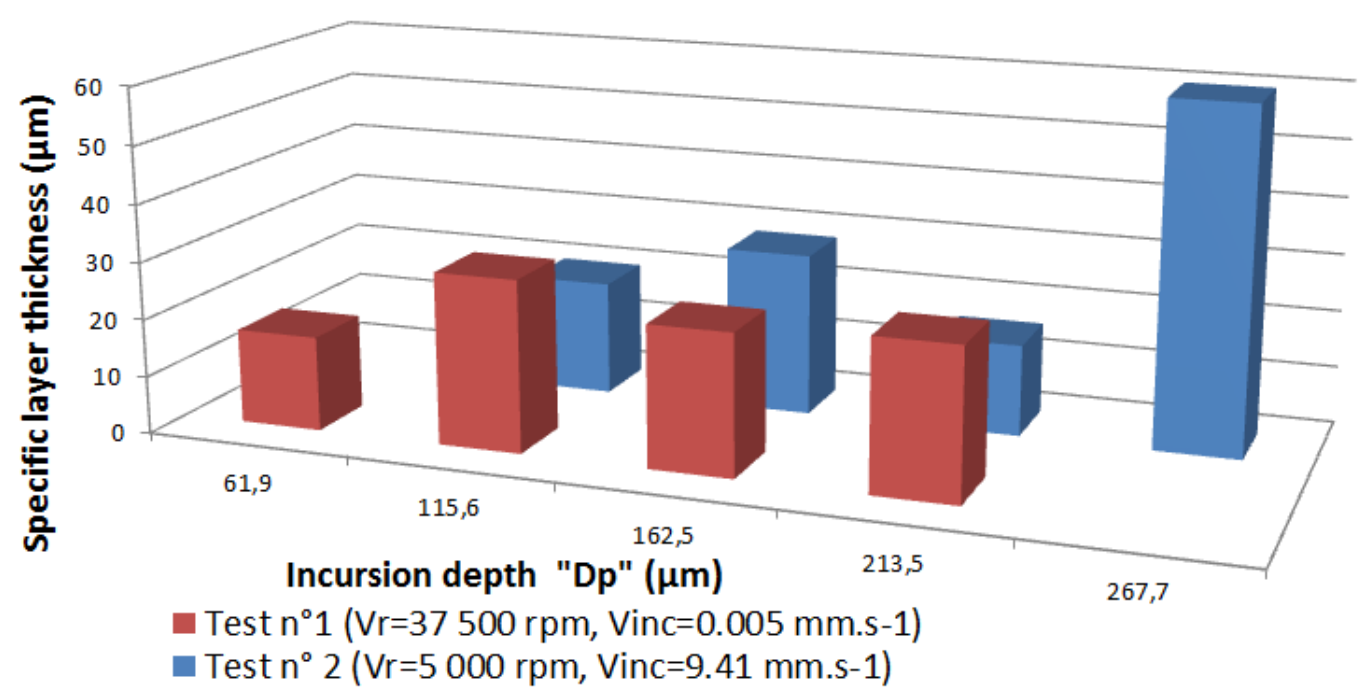

Fig. 24. Maximal adhering layer thickness depending on the incursion depth $D_{p}$ and the test series conditions.

seal tooth were performed using a high-speed test rig in order to improve a better understanding of the Al-Si $6 \%$ behavior under severe labyrinth/coating high speed contact. The Al-Si $6 \%$ tribological behavior was studied and simulated following two severe tribological conditions. The first severe wear conditions is characterized by a high number of labyrinth seal revolutions and an associated rubbed length for the first one, whereas the second severe rubbing condition is described with a high feed-rate leading to a high abradable material flow. Additional experimental interaction data are provided by developing a special instrumentation composed of contact forces, accelerometers, thermocouples, contact condition and acoustic emissions sensors, able to simultaneously record with different synchronized signals of sampling frequency coming from the incursion tests. Successive incursion depths, separated from each other by a distance of $50 \mu \mathrm{m}$ have been simulated to perform allowing visual post-tests worn material examinations depending on the interaction time. The results showed that:

- The Al-Si 6\% behavior (subjected to the first tribological condition) is mainly characterized by a discontinuous abrasion wear mechanism composed of successive and periodic Al-Si $6 \%$ wrenching. In addition to the contact surfaces impact during the interaction, a significant Al-Si $6 \%$ behavior change is observed over a certain incursion depth, and enables the labyrinth seal tooth material transfer inside the Al-Si $6 \%$ coating. The occurrence of an adhesive wear mechanism can explain the combined increase of friction coefficient and temperature.

- Concerning the second tribological condition, the Al-Si $6 \%$ coating is subjected to similar wear mechanisms. The Al-Si $6 \%$ behavior is significantly affected after two labyrinth seal rotations with an increase of the friction coefficient. The different frequency signatures (corresponding to one labyrinth seal rotation) are highlighted using the time-frequency analy- sis of the acoustic emission signals. According to many study available on the literature, these frequency signatures may be associated to different wear mechanisms which defined the Al-Si $6 \%$ abradable coating behavior.

The wear dynamic have been better studied by considering a third body approach on both test conditions. The first body (the Al-Si 6\% coating) is mainly damaged and deformed, forming rub-grooves with different characteristics. The second first body (the labyrinth seal tooth) is practically not deformed and weared. Two different varieties of particles production have been identified; a ductile and an adhering layer on the rub-groove bottom and pulverulent fine powder particles, relatively not cohesive (probably as oxide) thus providing two different kind of third body. The particles detachment from Al-Si $6 \%$ and labyrinth seal tooth (first bodies) generates the source flow thus creating the adhering layer. It is mainly composed of aluminium and silicon (second test conditions) but also of a blend of labyrinth seal tooth materiel transferred (first test conditions).

Finally, it has been demonstrated that the evolution of the third body and his life cycle during the contact have a major impact on the final rub-groove morphology. This study should be complemented by precisely evaluating particles ejected during the interaction (size, chemical composition), effects of the labyrinth seal rotation and incursion on both material flows to established the life of the contact according to the overall interaction parameters.

Acknowledgements. These investigations were supported by the European Commission through the FP7 E-BREAK project under Grant Agreement No. 314366 and by SAFRANTURBOMECA. The study also received financial support of the Agence Nationale de la Recherche et de la Technologie (ANRT). The support of these organisation is gratefully acknowledged. 


\section{References}

[1] M. Dorfman, U. Erning, J. Mallon, Gas turbines use abradable coatings for clearance-control seals, Seal. Technol. 97 (2002) 7-8

[2] W. Dalzell, S. Sanders, G. Crawford, F. Walden, W. Woodard, Abradable seal having improved properties, US Patent No. 6352 264, 2002

[3] G. Jacquet-Richardet, M. Torkhani, P. Cartraud, F. Thouverez, T. N. Baranger, M. Herran, C. Gibert, S. Baguet, P. Almeida, L. Peletan, Rotor to stator contacts in turbomachines. review and application, Mech. Syst. Signal Process. 40 (2013) 401-420

[4] R. Schmid, F. Ghasripoor, M. Dorfman, X. Wie, An overview of compressor abradable thermal sprays, in: Surface Engineering International Thermal Spray Conference ITSC, 2000, pp. 406-412

[5] P. Dowson, M. Walker, A. Watson, Development of abradable and rub-tolerant seal materials for application in centrifugal compressors and steam turbines, Seal. Technol. 12 (2004) 5-10

[6] Y. Maozhong, H. Baiyun, H. Jiawen, Erosion wear behaviour and model of abradable seal coating, Wear 252 (2002) 9-15

[7] M. Cuny, Contribution to the local characterization of pairs of materials involved during rotor/stator contact in a turbomachine, Ph.D. thesis, Université de Lorraine, 2012

[8] S. Baïz, Experimental study of blade/abradable contact: contribution to the mechanical characterization of abradable materials and their dynamic interaction on rotating test bench with a rotating test rig with a blade, Ph.D. thesis, Ecole centrale de Lille, 2011

[9] M. Proctor, J. Delgado, Leakage and power loss test results for competing turbine engine seals, in: ASME Turbo Expo 2004: Power for Land, Sea, and Air, 2004, pp. 441451

[10] I. Delgado, M. Proctor, Continued investigation of leakage and power loss test results for competing turbine engine seals, Tech. rep., NASA/TM-2006-214420 (2006)

[11] D. Collins, J. Teixeira, P. Crudgington, The degradation of abradable honeycomb labyrinth seal performance due to wear, Seal. Technol. 8 (2008) 7-10

[12] D. Rhode, R. Hibbs, Clearance effects on corresponding annular and labyrinth seal flow leakage characteristics, J. Tribol. 115 (1993) 699-704
[13] A. Gamal, J. Vance, Labyrinth seal leakage test: tooth profile, tooth thickness, and eccentricity effects, ASME J. Eng. Gas Turbines Power 130 (2008) 11

[14] L. Dobek, Labyrinth seal testing for lift fan engines, Tech. rep., Pratt and Whitney Aircraft Division United Aircraft Corporation, 1973

[15] J. Denecke, V. Schramm, S. Kim, S. Wittig, Influence of rub-grooves on labyrinth seal leakage, in: ASME Turbo Expo 2002: Power for Land, Sea, and Air, American Society of Mechanical Engineers, 2002, pp. 771-779

[16] P. Dowson, S. Ross, C. Schuster, The investigation of suitability of abradable seal materials for application in centrifugal compressors and steam turbines, in: Proceedings of the twentieth turbomachinery symposium, 1991

[17] J. Whalen, E. Alvarez, L. Palliser, Thermoplastic labyrinth seals for centrifugal compressors, in: Proceeding of the thirty third Turbo Symposium, 2004

[18] Z. Mutasim, L. Hsu, E. Wong, Evaluation of plasma sprayed abradable coatings, Surf. Coat. Technol. 54 (1992) 39-44

[19] S. Wilson, Ensuring tight seals, Tech. rep., Sulzer Technical Review 2, 2007

[20] C. Delebarre, V. Wagner, J. Paris, G. Dessein, J. Denape, J. Gurt-Santanach, An experimental study of the high speed interaction between a labyrinth seal and an abradable coating in a turbo-engine application, Wear 316 (2014) 109-118

[21] A. Hase, H. Mishina, M. Wada, Correlation between features of acoustic emission signals and mechanical wear mechanisms, Wear 292-293 (2012) 144-150

[22] L. Marinescu, D. Axinte, A time frequency acoustic emission-based monitoring technique to identify workpiece surface malfunctions in milling with multiple teeth cutting simultaneously, Int. J. Machine Tools Manuf. 49 (2009) 53-65

[23] M. Noone, R. Mehan, Observation of crack propagation in polycrystalline ceramics and its relationship to acoustic emissions, in: Concepts, Flaws, and Fractography, Springer, US, 1974, Vol. 1, pp. 201-229

[24] A. Prillieux, L. Talotte, Determining the evolution of the mechanical properties of alsi and abradable almn aluminum base., Tech. rep., Institut Carnot Cirimat, 2013

[25] G. Chen, Z. Zhou, Time-frequency analysis of frictioninduced vibration under reciprocating sliding conditions, Wear 262 (2007) 1-10

[26] Y. Berthier, P. Kapsa, L. Vincent, Material and contacts: A tribological approach, 1998 